\title{
UK Renal Registry 11th Annual Report (December 2008): Chapter 7 Survival and causes of death of UK adult patients on Renal Replacement Therapy in 2007: national and centre-specific analyses
}

\author{
David Ansell ${ }^{\mathrm{a}}$, Paul Roderick ${ }^{\mathrm{b}}$, Alex Hodsman ${ }^{\mathrm{a}}$, Daniel Ford ${ }^{\mathrm{a}}$, Retha Steenkamp ${ }^{\mathrm{a}}$ and \\ Charlie Tomson $^{a}$ \\ aUK Renal Registry, Bristol, UK; ${ }^{\mathrm{b}}$ Institute of Public Health Medicine, Southampton General Hospital, UK
}

\section{Key Words}

Cause of death - Comorbidity · Dialysis - ESRD - ESRF . Haemodialysis . Outcome . Peritoneal dialysis - Renal Replacement Therapy · Survival · Transplant · Vintage

\begin{abstract}
Introduction: These analyses examine survival from the start of renal replacement therapy (RRT), based on the total incident UK dialysis population reported to the Registry, including the $21 \%$ who started on PD and the $5 \%$ who received a pre-emptive transplant. Survival of prevalent patients and changes in survival between 1997-2006 are reported. The article includes a discussion on the technical definition for the date of start of both PD and HD. Methods: Survival was calculated for both incident and prevalent patients on RRT and compared between the UK countries after adjustment for age. Survival of incident patients (starting during 2006) was calculated with and without a 90 day RRT start cut off. Survival of incident
\end{abstract}

\section{KARGER}

Fax +4161306 1234 E-Mail karger@karger.ch www.karger.com
C 2009 S. Karger AG, Basel

$1160-2110 / 09 / 1115-0113 \$ 26.00 / 0$

Accessible online at: www.karger.com/nec patients is shown with and without censoring at transplantation. Both the Kaplan-Meier and Cox adjusted models were used to calculate survival. Causes of death were analysed for both groups. Relative risk of death was calculated compared with the general UK population. Results: The 2006 unadjusted 1 year after 90 day survival for patients starting RRT was $86 \%$. In incident 18-64 year olds the unadjusted 1 year survival had risen from $85.9 \%$ in 1997 to $91.5 \%$ in 2006 and for those aged $\geqslant 65$ it had risen from $63.8 \%$ to $72.9 \%$. The age adjusted survival of prevalent dialysis patients rose from $85 \%$ in 2000 to $89 \%$ in 2007. Diabetic patient survival rose from $76.6 \%$ in 2000 to $84.0 \%$ in 2007. The relative risk of death on RRT compared with the general population was 30 at age 30 years compared with 3 at age 80 years. In the prevalent RRT dialysis population, cardiovascular disease accounted for $34 \%$ of deaths, infection $20 \%$ and treatment withdrawal $14 \%$. Conclusions: Incident and prevalent patient survival on RRT in all the UK countries for all age ranges and also for patients with diabetes continued to improve. The relative risk of death on RRT compared with the general population has fallen since 2001. Death rates on dialysis in the UK 
remained lower than when compared with a similar aged population on dialysis in the USA.

\section{Introduction}

The analyses presented in this chapter examine survival both from the start of renal replacement therapy (RRT) and of prevalent patients. They encompass the outcomes from the total incident UK dialysis population reported to the UK Renal Registry (UKRR), including the $21 \%$ who started on peritoneal dialysis and also the $5 \%$ who received a pre-emptive transplant. These results therefore show a true reflection of the whole UK RRT population. Additionally, 1st year UK survival data included patients who had died within the first 90 days of starting RRT, a period excluded from most other countries' registry data.

The term Established Renal Failure (ERF) used throughout this chapter is synonymous with the terms of End Stage Renal Failure (ESRF) and End Stage Renal Disease (ESRD) which are in more widespread international usage. Within the UK, patient groups have disliked the term 'End Stage' which formerly reflected the inevitable outcome of this disease.

In the UKRR 2006 Report, with the agreement of all UK clinical directors, centre anonymity for survival analyses was removed. It is again stressed that these are raw data which require very cautious interpretation. The UKRR can adjust for the effects of the different age distributions of patients in different centres, but lacks sufficient data from many participating centres to enable adjustment for comorbidity and ethnic origin, which have been shown to have a major impact on outcome (e.g. better survival is expected in centres with a higher proportion of Black and South Asian patients). With this lack of information on case mix, it is difficult to interpret any apparent difference in survival between centres. Using data only from those centres with greater than $85 \%$ complete data returns on comorbidity, an analysis has been undertaken to highlight the impact of changes in estimates of survival rates by centre after adjusting for age, primary renal diagnosis and comorbidity. It is hoped this will encourage all centres to allocate the resources to return the comorbidity data.

Despite the uncertainty about any apparent differences in outcome for centres which appear to be outliers, the UKRR will follow the clinical governance procedures as set out in chapter 2 .
This year some analyses on causes of death are included within this chapter.

\section{Methods}

The unadjusted survival probabilities (with 95\% confidence intervals) were calculated using the Kaplan-Meier method, in which the probability of surviving more than a given time can be estimated for members of a cohort of patients, without accounting for the characteristics of the members of that cohort. Where centres are small, or the survival probabilities are greater than $90 \%$, the confidence intervals are only approximate.

In order to estimate the difference in survival of different subgroups of patients within the cohort, a stratified proportional hazards model (Cox) was used where appropriate. The results from the Cox model were interpreted using a hazard ratio. When comparing two groups, the hazard ratio is the ratio of the estimated hazards for group A relative to group B, where the hazard is the risk of dying at time $t$ given that the individual has survived until this time. The underlying assumption of a proportional hazards model is that this ratio remains constant throughout the period under consideration. Whenever used, the proportional hazards model was tested for validity.

To allow comparisons between centres with differing age distributions, survival analyses were statistically adjusted for age and reported as survival adjusted to age 60 . This age was chosen because it was approximately the average age of patients starting RRT 10 years ago at the start of the Registry's data collection. The average age of patients commencing RRT in the UK in 2006 was approximately 65 years, but the Registry has maintained age adjustment to 60 years for comparability with previous years' analyses. All analyses were undertaken using SAS v 9.1.3.

\section{Definition of the date renal replacement therapy started}

The incident survival figures quoted in this chapter are from the first day of renal replacement therapy. When a patient starts RRT with a pre-emptive transplant there is an easily definable date. Ongoing UKRR analyses of electronic data extracted for the immediate month prior to the start date of RRT provided by the clinician have highlighted inconsistencies in the definition of this first date when patients start either on haemodialysis or peritoneal dialysis. This concern will not be unique to the UK but will be common to analyses from all renal registries and to any comparison between published studies reported from different centres.

The variability in the date decided as the start of $\mathrm{PD}$ is attributable to the lack of an agreed national or international definition. Clinical staff may use the date the PD catheter was inserted, the date of the first dialysis exchange, the date training started or the date of discharge home on daily PD. This variability between centres may lead to a small lead time survival bias, but is a critical date when analysing the influence of biochemical variables in the period prior to starting $\mathrm{PD}$ on longer term outcomes.

The UK Renal Association PD Working Group has now agreed a preliminary clinical definition: 
The date of start of peritoneal dialysis is defined as the date of first PD fluid exchange given with the intention of causing solute or fluid clearance

This contrasts with an exchange solely for confirming or maintaining catheter patency. In general, exchanges which are part of PD training should be considered as the start of PD. However, if it is not planned that the patient starts therapy at that time, several exchanges as part of training need not necessarily be considered the start of dialysis.

A similar problem has also been highlighted with the biochemistry data of patients starting haemodialysis. Investigation of patient level data from renal clinical IT systems has shown that some patients have had several episodes of haemodialysis (sometimes even a week or more apart) in the weeks prior to that defined in the IT system as the start date of RRT. This may only have been for fluid overload, but has resulted in significant sustained improvements in the patients' biochemistry.

In addition to this varying clinical definition of day 0 , there is international variability on when patient data are collected by national registries, with some countries (often for financial reimbursement reasons) defining the 90th day after starting RRT as day 0 or others collecting data only on those who have survived 90 days and reporting as zero the number of patients dying within the first 90 days. In the UK all patients starting RRT are included from the date of the first RRT treatment (a date currently defined by the clinician) unless they recover renal function within 90 days. However, this has relied on clinicians retrospectively assigning the date of first RRT in patients who present acutely but do not recover, and it has become clear that this is not a uniform practice, with other clinicians recording the date on which the patient first started outpatient dialysis, or the date on which it was decided to plan for long-term RRT. The UK data therefore include some patients who develop acute irreversible renal failure in the context of an acute illness for instance and were recorded by the clinician as being in irreversible established renal failure. However, other such patients may not be managed by nephrologists or may be categorised as 'acute renal failure' on the timeline screen which the extraction software uses to flag a patient's data for extraction and submission to the UKRR. These variations have highlighted the need for clearer instructions to UK nephrologists on how to classify such patients.

Due to this variability between countries, in many instances in this chapter survival from day 90 onwards is also reported as this allows comparison with many other registries, including the US, which mainly record data from day 90 onwards. Although the USRDS 2008 data is now reporting on survival data from day 0 , their initial reporting of a lower rate of death which then increases throughout the first 90 day period probably indicates the variable reporting of patients who do not survive this period. This distinction is important, as there is a much higher death rate in the first 90 days which would distort any international comparisons.

\section{Methodology for incident patient survival}

The incident survival cohort was NOT censored at the time of transplantation and therefore included the $5 \%$ who received a preemptive transplant. Censoring excluded the healthier patient cohort. An additional reason for not censoring was to facilitate comparison between centres. Centres with a high proportion of patients of South Asian origin are likely to have a healthier dialysis population, because South Asian patients are less likely to undergo early transplantation.

The take-on population in any specific year included patients who recovered from established renal failure (ERF) after 90 days from the start of RRT, but excluded those that recovered within 90 days. Patients newly transferred into a centre who were already on RRT were excluded from the take-on population for that centre and were counted at the centre on which they started RRT. Patients restarting dialysis after a failed transplant were also excluded (unless they started RRT in that current year).

For patients who recovered renal function for $>90$ days and then went back into ERF, the length of time on RRT was calculated from the day on which the patient restarted RRT. If recovery was for less than 90 days, the start of renal replacement therapy was calculated from the date of the first episode and the recovery period ignored.

The one year incident survival for patients in 2006 was calculated for those who had all been followed for 1 full year through 2006 and 2007 (e.g. patients starting RRT on 1st December 2006 were followed through to 30th November 2007). The 2007 incident patients were excluded from this year's incident survival analysis as they had not been followed for a sufficient length of time.

For analysis of 1 year after 90 day survival, patients who started RRT in October through December 2006, were not included in the cohort, as 1st quarter 2008 data on these patients were not yet available.

It is important to note that in the 1 year after 90 day survival analyses in the 2005 UKRR Report and all reports prior to 2005, the previous year's patient cohort was used to calculate the 1 year after 90 day survival (e.g. this year the alternative would have been to use the 2005 rather than 2006 cohort) starting in October. A comparison of these two methods has shown no difference between them for any but the smallest centres (which will have wide $95 \%$ confidence intervals), so for simplicity of understanding the cohort and using a common cohort across analyses, the UKRR will now use the previous year's data (2006 cohort).

To help identify any centre differences in survival from the small centres (where confidence intervals are large), an analysis of 1 year after 90 day survival using a rolling 4 year combined incident cohort from 2003 to 2006 was also undertaken. For those centres which had joined the UKRR in the previous 1-3 years, the available data were included.

The death rate per 100 patient years was calculated by counting the number of deaths and dividing by the person years exposed. This included all patients, including those who died within the first 3 months of therapy. The person years at risk were calculated by adding up, for each patient, the number of days at risk (until they died or transferred out) and dividing by 365 .

Adjustment of 1 year after 90 day survival for the effect of comorbidity was undertaken using a rolling 5 year combined incident cohort from 2002 to 2006 . For the 5 years combined, 8 centres had returned $>85 \%$ of comorbidity data for patients. Adjustment was first performed to a mean age of 60 years, then to the average primary diagnosis mix for all the eight centres. The individual centre data were then further adjusted for average comorbidity mix present at these centres.

The survival hazard function was calculated as the probability of dying in a short time interval considering survival to that interval. 


\section{Methodology for prevalent patient survival}

All patients who had been established on RRT for at least 90 days on 1 January 2007 were included in this analysis. The patients in the transplant cohort had all been established with a transplant for at least 6 months.

As discussed in previous reports, comparison of survival of prevalent dialysis patients between centres is complex. Survival of prevalent dialysis patients can be studied with or without censoring at transplant. When a patient is censored at transplantation, the patient is considered as alive up to the point of transplantation, but the patient's status post-transplant is not considered. Therefore a death following transplantation is not taken into account in calculating the survival figure. This censoring could cause apparent differences in survival between those renal centres with a high transplant rate and those with a low transplant rate, especially in younger patients where the transplant rate is highest. The differences are likely to be small due to the low post-transplantation mortality rate and the relatively small proportion of patients being transplanted in a given year compared to the whole dialysis population (usually less than $7 \%$ of the total dialysis population). To estimate the potential differences, the results for individual renal centres were compared with and without censoring at transplant. Overall there was a $0.2 \%$ higher survival using the uncensored data. With such small differences only the uncensored results have been quoted throughout the prevalent analyses.

\section{Methodology of causes of death}

Cause of death were sent in by renal centres as an EDTA-ERA registry code (appendix G). These have been grouped into the following categories:

Cardiac disease

Cerebrovascular disease

Infection

Malignancy

Treatment withdrawal

Other

Uncertain
Some centres had high data returns to the UKRR regarding cause of death, whilst others returned no information.

Adult patients aged 18 years and over, from England, Wales, Scotland and Northern Ireland, were included in the analyses on cause of death. The incident patient analysis included all patients starting RRT in the years 2002-2006. Previously, data analysis was limited to centres with a high rate of return for cause of death. When this was compared with an analysis of all the cause of death data on the database, the percentages in corresponding EDTA categories remained unchanged so the latter data were therefore included.

Analysis of prevalent patients included all those aged over 18 years and receiving RRT on $1 / 1 / 2007$. The death rate was calculated for the UK general population (data from ONS http:// www.statistics.gov.uk/statbase/Product.asp?vlnk=14409) by age band and compared with the same age band for prevalent patients on RRT on $1 / 1 / 2007$.

\section{Results of incident (new RRT) patient survival}

The 2006 cohort included 6,311 patients who were starting RRT (table 7.1).

\section{Comparison with audit standards}

The current 2007 4th UK Renal Standards document [1] does not set any standards for audit of patient survival. This is in contrast to the 2002 3rd UK Renal Standards document [2] (http://www.renal.org/standards/ standards.html) which concluded that:

It is hard to set survival standards at present because these should be age, gender and co-morbidity adjusted and this is not yet possible from Registry data. The last Standards document (2nd - 1998)

Table 7.1. Summary of the exclusions from the incident cohorts

\begin{tabular}{|c|c|c|c|c|c|}
\hline & \multicolumn{5}{|c|}{ Cohort year } \\
\hline & 2006 & 2005 & 2004 & 2003 & 2002 \\
\hline All incident patients & 6,322 & 6,060 & 5,411 & 4,755 & 4,284 \\
\hline Exclusion category (1) & -1 & -1 & -4 & -3 & -2 \\
\hline Exclusion category (2) & -6 & -5 & -2 & -5 & -1 \\
\hline Exclusion category (3) & -4 & -10 & -14 & -11 & -19 \\
\hline Remaining incident cohort & 6,311 & 6,044 & 5,391 & 4,736 & 4,262 \\
\hline Died within 90 days of start & -460 & -475 & -484 & -449 & -428 \\
\hline Lost within 90 days of start & -29 & -15 & -30 & -15 & -12 \\
\hline Centres not contributing to UKRR & -25 & -13 & -16 & -23 & -18 \\
\hline Cohort at 1 yr after 90 days & 5,797 & 5,541 & 4,861 & 4,249 & 3,804 \\
\hline Deaths at one year after 90 days & 786 & 821 & 777 & 653 & 680 \\
\hline
\end{tabular}

(1) patient had 2nd start in same year: if recovery $<90 \mathrm{~d}$, used 1st start date, if recovery $\geqslant 90 \mathrm{~d}$ used 2 nd start date

(2) recovery <90d: used 1st start date in previous year(s) which is not in this cohort - delete from current cohort

(3) recovery $\geqslant 90 \mathrm{~d}$ : should use 2 nd start date in next year(s) which is not in this cohort - delete from current cohort 
Table 7.2. One-year patient survival (from day 0-365), patients aged 18-54, 2006 cohort

\begin{tabular}{lcc}
\hline First treatment & $\begin{array}{c}\text { Standard primary } \\
\text { renal disease }\end{array}$ & $\begin{array}{c}\text { All primary renal } \\
\text { diseases except } \\
\text { diabetes }\end{array}$ \\
\hline All Dialysis \% & 95.7 & 94.8 \\
$95 \%$ CI & $94.1-96.8$ & $93.4-95.8$ \\
HD \% & 93.9 & 93.2 \\
$95 \%$ CI & $91.8-95.5$ & $91.4-94.6$ \\
PD \% & 99.1 & 98.5 \\
$95 \%$ CI & $97.1-99.7$ & $96.7-99.3$ \\
\hline
\end{tabular}

recommended at least $90 \%$ one year survival for patients aged 18-55 years with standard primary renal disease. This may have been too low as the rate in participating centres in the Registry was 97\%, though numbers were small.

The 3rd Renal Standards document defines standard primary renal disease using the EDTA-ERA diagnosis codes (including only codes 0-49) (appendix G); this excludes patients with renal disease due to diabetes and other systemic diseases. It is more widespread practice to simply exclude patients with diabetes, so these analyses were also included in this report to allow comparison with reports from other registries. The results are shown in table 7.2 and are similar to the previous year.

\section{Between country}

Two years incident data have been combined to increase the size of the patient cohort, so that any differences between the 4 UK countries are more likely to be identified (table 7.3). These data have not been adjusted for differences in primary renal diagnosis, ethnicity or comorbidity, nor for differences in life expectancy in the general populations of the four countries. There was no significant difference in 90 day survival between UK countries $(\mathrm{p}=0.8)$, although the 1 year after 90 day survival differed significantly $(\mathrm{p}=<0.0001$, Chi Squared). The greater prevalence of cardiovascular disease in Wales and Scotland compared with England may account for these differences.
Table 7.4. One-year after day 90 survival by first established treatment modality (adjusted to age 60)

\begin{tabular}{lcc}
\hline & \multicolumn{2}{c}{ Adjusted 1 year after 90 days \% } \\
& \multicolumn{2}{c}{$95 \%$ CI } \\
\cline { 2 - 3 } Year & HD & PD \\
\hline 2006 & 87.2 & 94.1 \\
& & $92.8-95.5$ \\
2005 & $86.0-88.3$ & 93.2 \\
& 85.8 & $91.8-94.6$ \\
2004 & $84.6-87.1$ & 90.4 \\
& 85.5 & $88.7-92.1$ \\
2003 & $84.2-86.8$ & 92.3 \\
& 85.0 & $90.7-93.9$ \\
2002 & $84.1-86.9$ & 90.2 \\
& 83.9 & $88.3-92.1$ \\
\hline
\end{tabular}

\section{Modality}

The age-adjusted one year survival estimates on HD and PD were $87.2 \%$ and $94.1 \%$ respectively which both showed a trend in improvement in survival from 2002 (table 7.4). There appeared to be better one year survival on PD compared with HD after age adjustment, similar to findings from the USRDS and Australasian (ANZDATA) registries. However, a straightforward comparison of the modalities in this way is misleading, given that in general, PD is used in younger patients and those with less severe comorbidity.

\section{Age}

Tables 7.5 to 7.10 show survival of all patients and those above and below 65 years of age, for up to eight years after initiation of renal replacement therapy. The UK is showing an improvement in both short and longer term survival on RRT for patients aged both under and over 65 years. As to be expected there was also a steep age related decline in survival over all time periods (see also figures 7.1 and 7.2).

If the survival data in tables 7.8 to 7.10 are calculated from day 90 ( 1 year after day 90 survival, 2 year after day 90 survival, etc) the survival in all cases increased by an

Table 7.3. Incident patient percentage survival across the UK countries, combined 2 year cohort (2005-2006), adjusted to age 60

\begin{tabular}{lccccc}
\hline & England & N Ireland & Scotland & Wales & UK \\
\hline \% 90 day & 95.0 & 94.9 & 94.9 & 94.1 & 94.3 \\
$95 \%$ CI & $94.5-95.5$ & $93.2-96.6$ & $93.2-95.5$ & $92.7-95.4$ & 86.6 \\
\% 1 year after 90 days & 89.0 & 90.8 & 85.2 & 88.6 & 84.3 \\
$95 \%$ CI & $88.3-89.7$ & $88.3-93.3$ & $83.2-87.2$ & $84.4-88.9$ & $87.9-89.2$ \\
\hline
\end{tabular}


Table 7.5. Unadjusted 90 day survival of new patients, 2006 cohort, by age

\begin{tabular}{lccc}
\hline Age & KM $^{*}$ survival (\%) & KM 95\% CI & N \\
\hline $18-64$ & 97.2 & $96.6-97.7$ & 3,165 \\
$\geqslant 65$ & 88.1 & $87.0-89.2$ & 3,145 \\
All ages & 92.7 & $92.0-93.3$ & 6,310 \\
\hline
\end{tabular}

* KM Kaplan-Meier.

Table 7.6. Unadjusted 1 year after day 90 survival of new patients, 2006 cohort, by age

\begin{tabular}{lccc}
\hline Age & KM survival (\%) & KM 95\% CI & N \\
\hline $18-64$ & 92.4 & $91.4-93.3$ & 3,044 \\
$\geqslant 65$ & 79.0 & $77.4-80.5$ & 2,753 \\
All ages & 86.0 & $85.1-86.9$ & 5,797 \\
\hline
\end{tabular}

additional 3-4\% across both age bands. These are the results most comparable to the figures quoted by the USRDS from the USA [3] and most other national registries, see chapter 14 .

There was a curvilinear increase in death rate per 1,000 patient years with age, shown in figure 7.2 for the period one year after 90 days. There were no differences between the UK countries.

The effect of censoring age related survival at the time of transplantation

The KM long term survival curves published in all reports prior to last year were censored at the time of

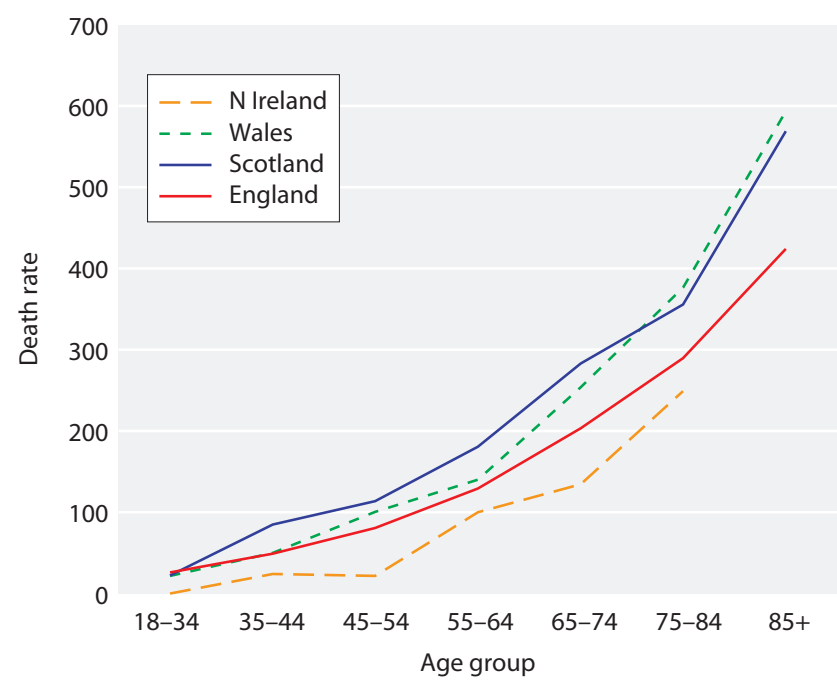

Fig. 7.2. One year after 90 days death rate per 1,000 patients years by UK country and age group for incident patients, 2003-2006 cohort

transplantation. This was not made clear in the description of methodology and although not incorrect, will make the longer term outcomes of younger patients (who are more likely to have undergone transplantation) appear worse than is actually the case. This is because only those younger patients remaining on dialysis (who may have more comorbidity than those transplanted) will have been included in the censored survival analysis. To demonstrate this difference in outcome between these two methods, figure $7.3 \mathrm{a}$ is

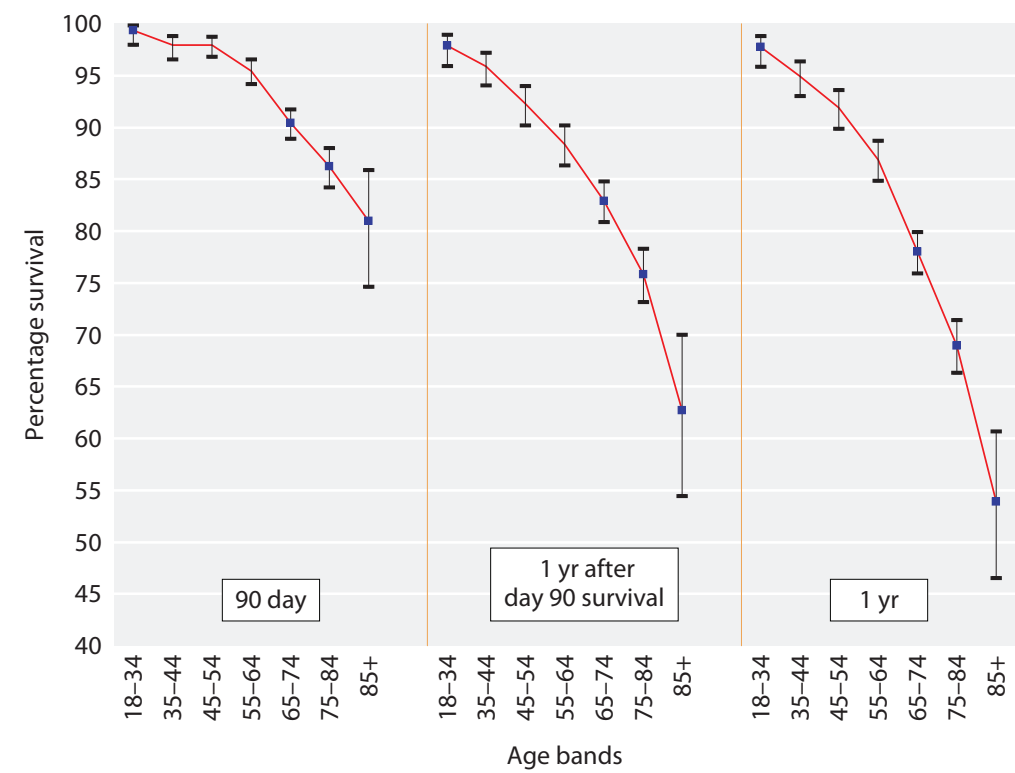

$\mathrm{c} 118$
Nephron Clin Pract 2009;111(suppl 1): c113-c139
Fig. 7.1. Unadjusted survival of all incident patients 2006 by age band
Ansell/Roderick/Hodsman/Ford/ Steenkamp/Tomson 

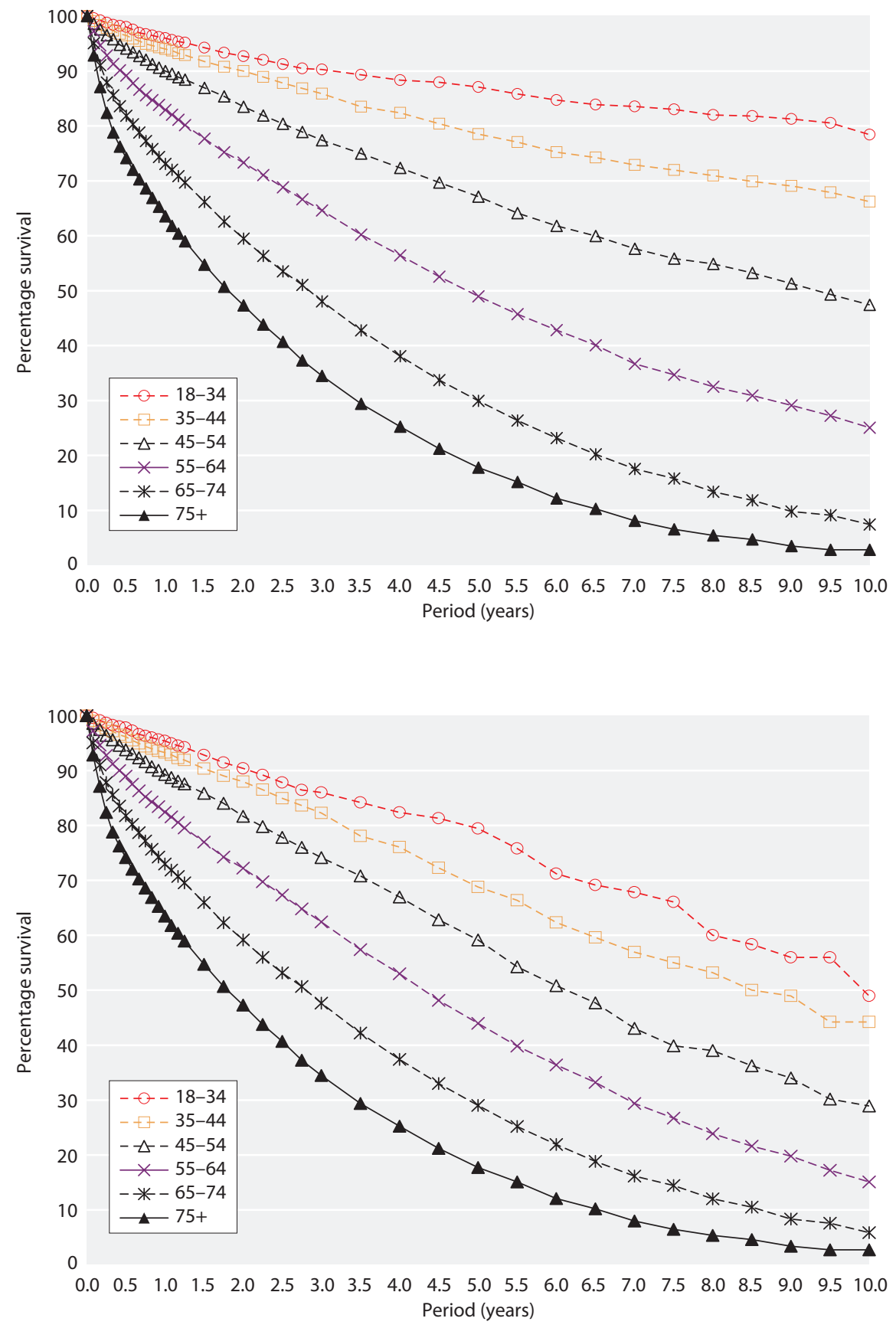

Fig. 7.3a. Kaplan-Meier 9-year survival of incident patients 1997-2006 cohort (from day 0 ), without censoring at transplantation
Fig. 7.3b. Kaplan-Meier 9-year survival of incident patients 1997-2006 cohort (from day 0 ), with censoring at transplantation shown below without censoring for transplantation and figure $7.3 \mathrm{~b}$ with censoring. In future reports it is planned to reproduce only the single figure of the longer term age related survival which is uncensored at the time of transplantation.

From figure 7.3a (uncensored), it can be seen that the $50 \%$ survival for a patient starting RRT in the UK aged 50,60 and 70 years is 9.5 years, 5 years and 3 years respectively.
The change in hazard of death by age, during the first 12 month period

Figure 7.4 shows the monthly hazard of death from the 1st day of starting RRT by age, which falls during the first 3-4 months. For patients aged over 55, the hazard of death was $60 \%$ lower in those patients who survived beyond 4 months. This same large reduction in hazard of death was not seen in the younger aged patients and will therefore affect proportionality in any 


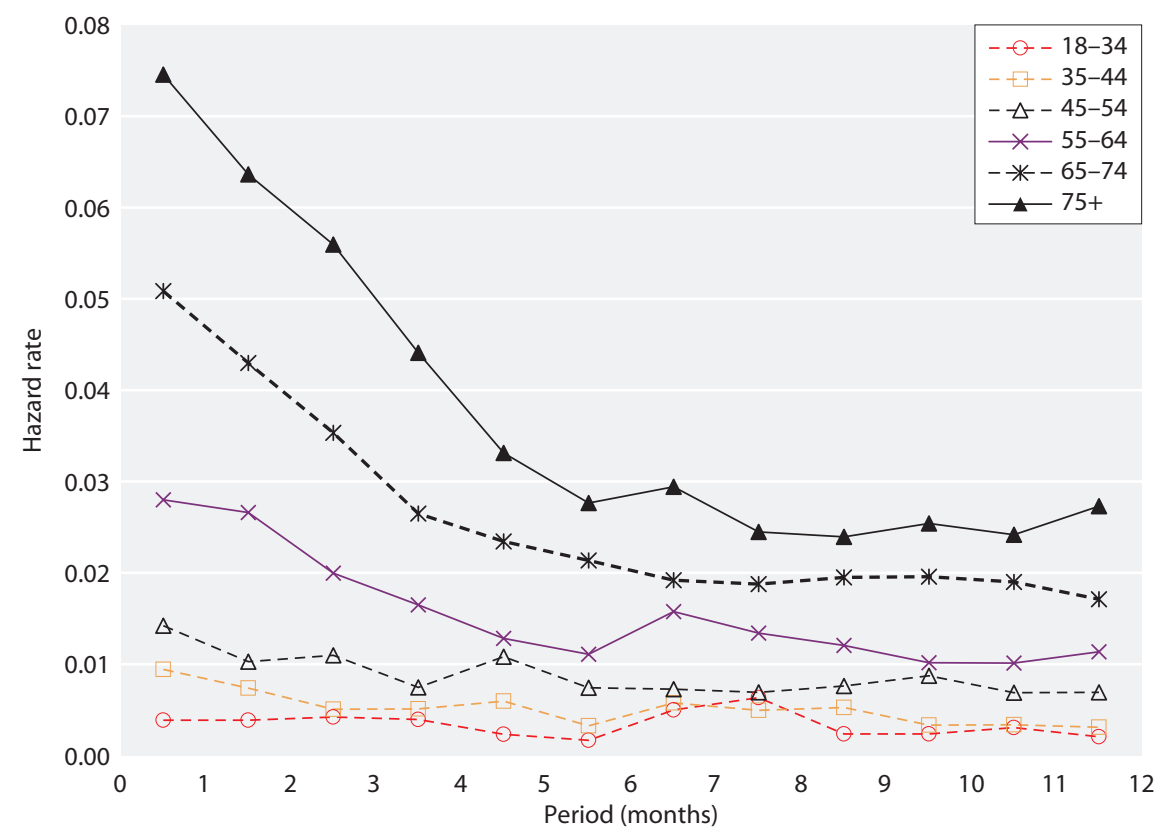

Fig. 7.4. First year monthly hazard of death, by age band 1997-2006 cohort
Cox model analysis that uses data starting from day zero and combines these different aged cohorts.

The USRDS in contrast reports a rising mortality in the first 3 month period [3] probably reflecting underreporting to the USRDS of patients that start on RRT who do not survive the first 90 days.

The hazard of death per each 10 year increase in patient age (unadjusted for primary renal disease) is shown in table 7.7.

\section{Changes in survival from 1997-2006}

The 1st year death rate per 1,000 patient years is shown in figure 7.5. These death rates are not directly comparable with those produced by the USRDS Registry, as the UK data included the first 90 day period where the death rates will be much greater. The death rate for patients aged over 65 years was unchanged from last year at 326 per 1,000 patient years, compared with a fall in the under 65 year age group from 110 per 1,000

Table 7.7. Increase in proportional hazard of death for each 10 year increase in age, at 90 days and for 1 year thereafter, 2006 cohort

\begin{tabular}{lcc}
\hline Interval & $\begin{array}{c}\text { Hazard of death for } 10 \\
\text { year age increase }\end{array}$ & 95\% CI \\
\hline First 90 days & 1.78 & $1.65-1.94$ \\
1 year after first 90 days & 1.61 & $1.52-1.71$ \\
\hline
\end{tabular}

patient years in 2005 to 89 per 1,000 patient years in 2006.

The unadjusted KM survival analyses (tables 7.8 and 7.9, figures 7.6 and 7.7) and annual death rates appear to be showing a large improvement in 1 to 7 year survival across the time periods for both the under and over $65 \mathrm{~s}$. This has happened even though the average age of patients starting RRT has risen by 5 years during this period. Survival amongst patients aged under 65 years at start of RRT has improved from $86 \%$ to $91.5 \%$. As

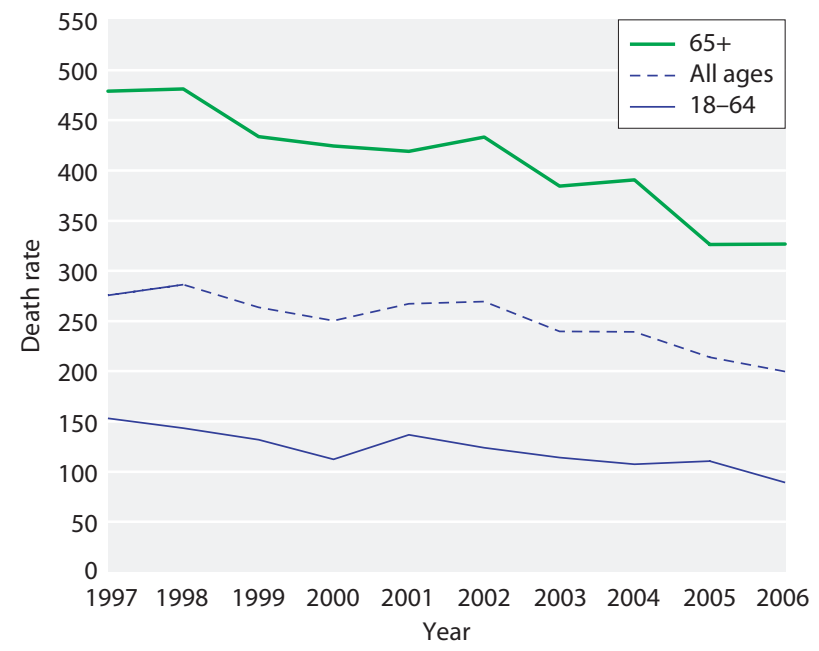

Fig. 7.5. One-year incident death rate per 1,000 patient years for all age groups 
Table 7.8. Unadjusted KM survival of incident patients 1997-2006 cohort for patients aged 18-64

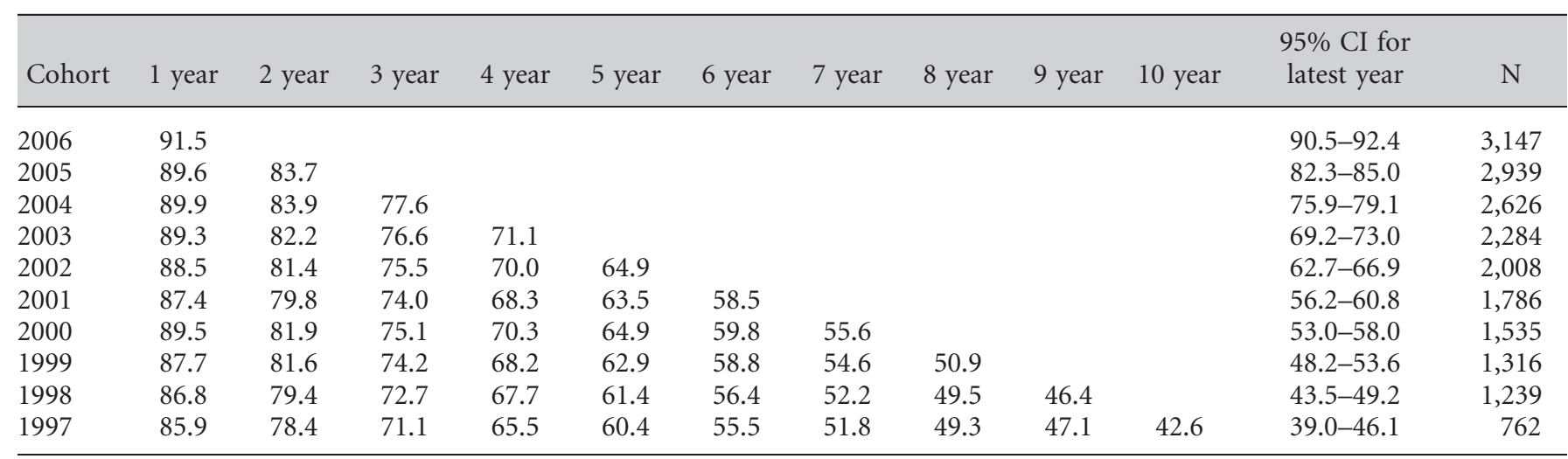

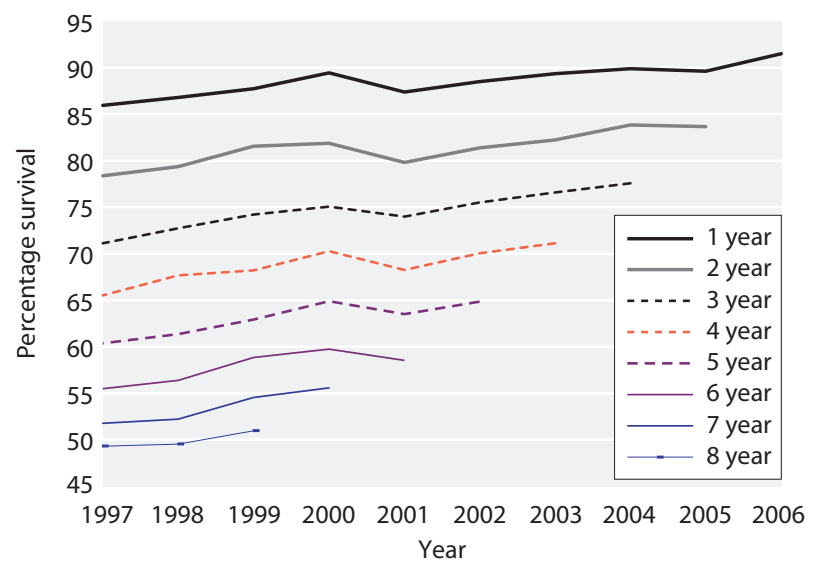

Fig. 7.6. Change in KM long term survival by year of starting RRT; for incident patients aged 18-64 years

survival rates were already high in these patients, the overall survival improvement was only 5\%. The reduction in the death rate (= relative survival improvement) in figure 7.5 shows that this equates to a $42 \%$ relative improvement over this 10 year period $(=4 \%$ annual improvement in the reduction in death rate).

Similarly for patients aged over 65 years there has been a $9 \%$ improvement in 1st year survival, which translates into a similar $32 \%$ relative reduction in death rate over this 10 year period.

A confounding factor may be the fact that additional renal centres have joined the UKRR over these intervening years. If they had better survival relative to existing centres, this would appear as a time trend. However separate analysis of survival in the earlier versus later centres has shown this not to be the case.

As these are observational data it is difficult to attribute this reduction in risk of death to any specific improvement in care. During this period mean haemoglobin in HD patients has shown annual improvement rising from $10.2 \mathrm{~g} / \mathrm{dl}$ in 1998 to $11.8 \mathrm{~g} / \mathrm{dl}$ in 2007 . Other improvements in phosphate and calcium control have been restricted to the last 4 years. This recent improvement contrasts with dialysis dose where the main improvements were in the first 4 years.

Table 7.9. Unadjusted KM survival of incident patients $1997-2006$ cohort for patients aged $\geqslant 65$

\begin{tabular}{|c|c|c|c|c|c|c|c|c|c|c|c|c|}
\hline Cohort & 1 year & 2 year & 3 year & 4 year & 5 year & 6 year & 7 year & 8 year & 9 year & 10 year & $\begin{array}{l}95 \% \text { CI for } \\
\text { latest year }\end{array}$ & $\mathrm{N}$ \\
\hline 2006 & 72.9 & & & & & & & & & & $71.3-74.4$ & 3,144 \\
\hline 2004 & 68.7 & 54.8 & 43.3 & & & & & & & & $41.4-45.1$ & 2,724 \\
\hline 2003 & 69.1 & 53.8 & 42.3 & 32.3 & & & & & & & $30.4-34.2$ & 2,363 \\
\hline 2002 & 65.9 & 51.4 & 40.9 & 32.7 & 25.3 & & & & & & $23.5-27.2$ & 2,169 \\
\hline 1999 & 66.3 & 50.6 & 38.4 & 28.7 & 21.5 & 15.3 & 10.9 & 8.5 & & & $7.0-10.1$ & 1,257 \\
\hline 1998 & 63.7 & 46.5 & 36.2 & 27.5 & 20.4 & 14.4 & 10.3 & 7.1 & 5.0 & & $3.8-6.4$ & 1,125 \\
\hline 1997 & 63.8 & 45.7 & 33.0 & 23.8 & 16.4 & 11.7 & 8.0 & 6.4 & 4.6 & 3.9 & $2.5-5.7$ & 575 \\
\hline
\end{tabular}




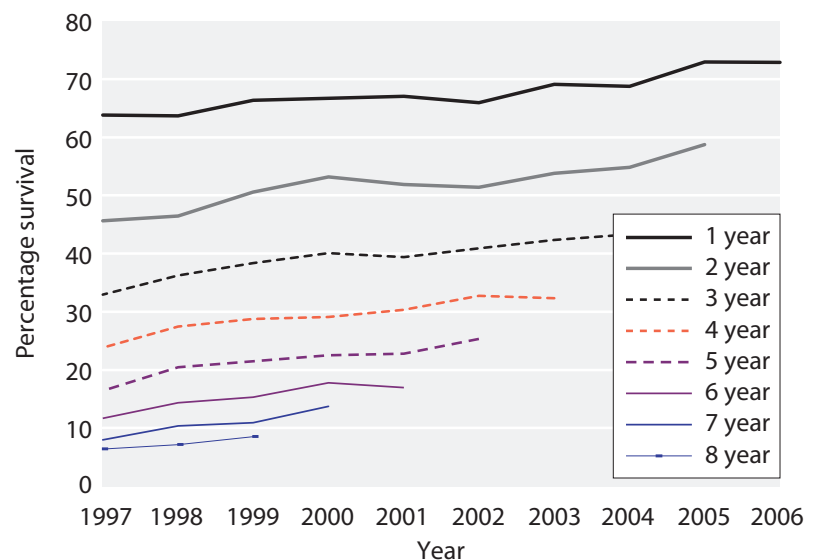

Fig. 7.7. Change in KM long term survival by year starting RRT; for incident patients aged $\geqslant 65$ years

\section{Change in survival on renal replacement therapy by vintage}

RRT patients in the UK continued to show no evidence of a worsening prognosis with time on RRT (vintage), even with the follow up period now increased to 10 years. Figure 7.8 demonstrates this clearly for patients aged under 65 years. For those patients aged 65 years and over, no vintage effect was seen within the first 7 years (after adjusting for the increasing age of the patient), though with the decreasing numbers remaining alive beyond 7 years the numbers become too small to draw any further conclusions. This lack of a 'vintage' effect was partly related to the effect of having a survivor cohort who were healthier than those patients who died early after starting RRT, which was then also partly offset by increasing comorbidity with time in the survivor cohort.

Figures 7.9 and 7.10 show these data for the non-diabetic and diabetic patients respectively with a suggestion of worsening prognosis in older diabetic patients.

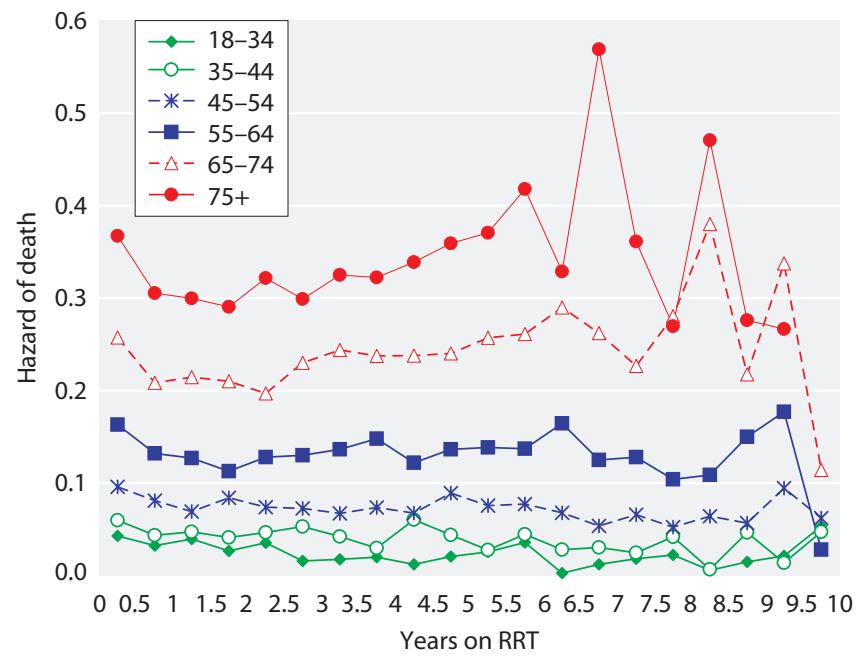

Fig. 7.8. Six monthly hazard of death, by vintage and age band, 1997-2006 incident cohort after day 90

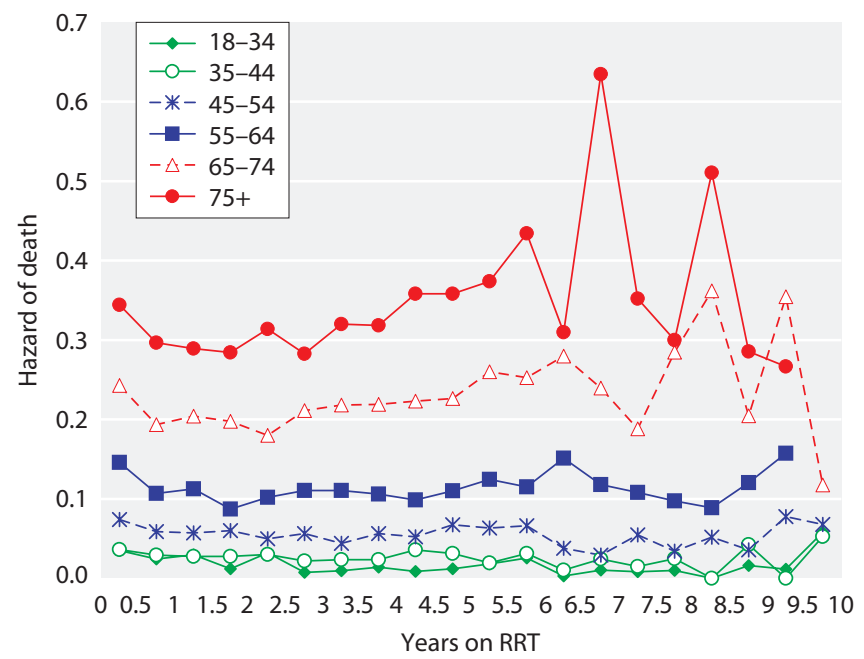

Fig. 7.9. Six monthly hazard of death, by vintage and age band, 1997-2006 non-diabetic incident cohort after day 90

Table 7.10. Unadjusted KM survival of incident patients 1997-2006 cohort for patients of all ages

\begin{tabular}{lcccccccccccc}
\hline Cohort & 1 year & 2 year & 3 year & 4 year & 5 year & 6 year & 7 year & 8 year & 9 year & 10 year & $\begin{array}{c}95 \% \text { CI for } \\
\text { latest year }\end{array}$ & $\mathrm{N}$ \\
\hline 2006 & 82.2 & & & & & & & & & & $81.2-83.1$ & 6,291 \\
2005 & 81.1 & 70.9 & & & & & & & & & $69.7-72.0$ & 6,015 \\
2004 & 79.2 & 69.1 & 60.1 & & & & & & & & $58.7-61.4$ & 5,350 \\
2003 & 79.2 & 67.9 & 59.2 & 51.4 & & & & & & & $49.9-52.9$ & 4,647 \\
2002 & 76.9 & 65.9 & 57.6 & 50.6 & 44.2 & & & & & & $42.7-45.8$ & 4,177 \\
2001 & 77.2 & 65.8 & 56.5 & 49.0 & 42.9 & 37.4 & & & & & $35.8-39.0$ & 3,632 \\
2000 & 78.4 & 67.9 & 58.0 & 50.3 & 44.2 & 39.2 & 35.0 & & & & $33.3-36.7$ & 3,028 \\
1999 & 77.4 & 66.7 & 56.9 & 49.2 & 42.8 & 37.7 & 33.3 & 30.2 & & & $28.4-32.0$ & 2,573 \\
1998 & 75.9 & 63.9 & 55.5 & 48.7 & 42.1 & 36.5 & 32.4 & 29.4 & 26.6 & & $24.8-28.5$ & 2,364 \\
1997 & 76.6 & 64.6 & 55.0 & 47.9 & 41.7 & 36.9 & 33.2 & 31.0 & 28.9 & 26.0 & $23.6-28.4$ & 1,337 \\
\hline
\end{tabular}




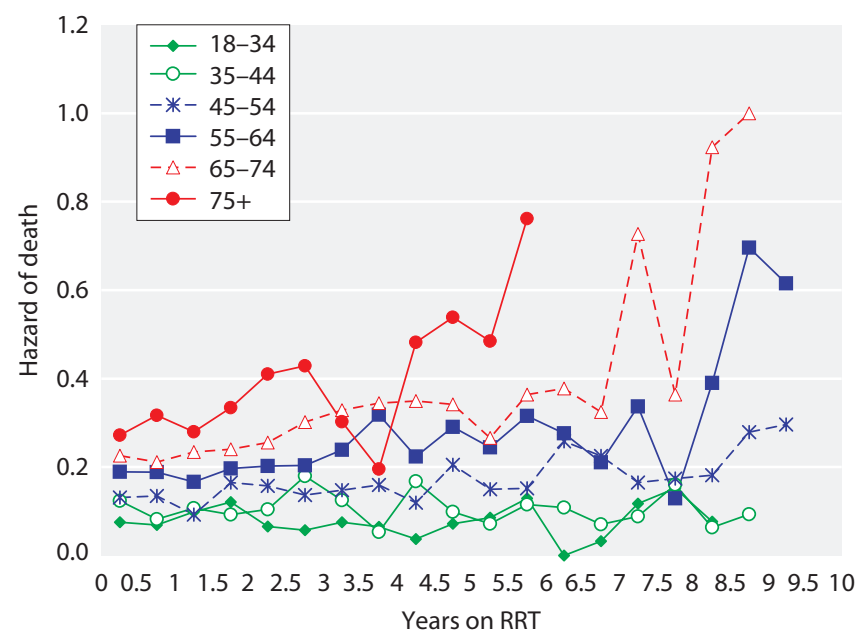

Fig. 7.10. Six monthly hazard of death, by vintage and age band, 1997-2006 diabetic incident cohort after day 90

Previously the USRDS has shown a worsening prognosis between being on RRT 1 year, 2-5 years and $>5$ years. In the latest USRDS Report [3] this difference in prognosis with time on RRT appears to have narrowed.

Time trend changes in incident patient survival, 1999-2006

The time trend changes are shown in figure 7.11.

\section{Analysis of centre variability in 1 year after 90 days} survival

The one year after 90 day survival for the 2006 incident cohort is shown in figure 7.12 for each renal centre. The tables for these data and for 90 day survival are given in appendix 1 at the end of this chapter (tables 7.24 and 7.25). The age adjusted individual centre survival for each of the last 8 years can also be found in appendix 1, table 7.26.
In the analysis of 2006 survival data, some of the smaller centres had wide confidence intervals (figure 7.12). This can be addressed by including a larger cohort, which will also assess sustained performance and as in previous reports has shown this as a rolling 4 year cohort, with the data in this report for the 4 year period 2003 to 2006. These data are presented as a funnel plot in figure 7.13. For any size of incident cohort (x-axis) one can identify whether any given survival rate ( $y$-axis) falls within plus or minus 2 standard deviations (SDs) from the national mean (solid lines, 95\% limits) or 3 standard deviations (dotted lines, 99.9\% limits). Table 7.11 allows centres to be identified on this graph by finding the number of patients treated by the centre and then looking up this number on the $\mathrm{x}$-axis.

There are 4 centres that fall between 2 and 3 standard deviations below average (Airdrie, Plymouth, Swansea and Glasgow) and 4 centres between 2 and 3 SDs above average (Kilmarnock, London Royal Free, London Guys and London St Bartholomew's). These data have not been adjusted for any patient related factor except age (i.e. not comorbidity, primary renal disease or ethnicity). The 3 London centres within the upper 2-3 SDs may reflect their higher ethnic minority mix with better survival, although this pattern is not seen in London Kings or other non-London centres with a high ethnic minority mix. These data have not been censored at transplantation, so the effect of differing centre rates of transplantation was not taken into account.

The analysis of Swansea data after adjustment for comorbidity (figure 7.14) indicates that patients at this centre had a higher comorbid burden when compared with other centres.

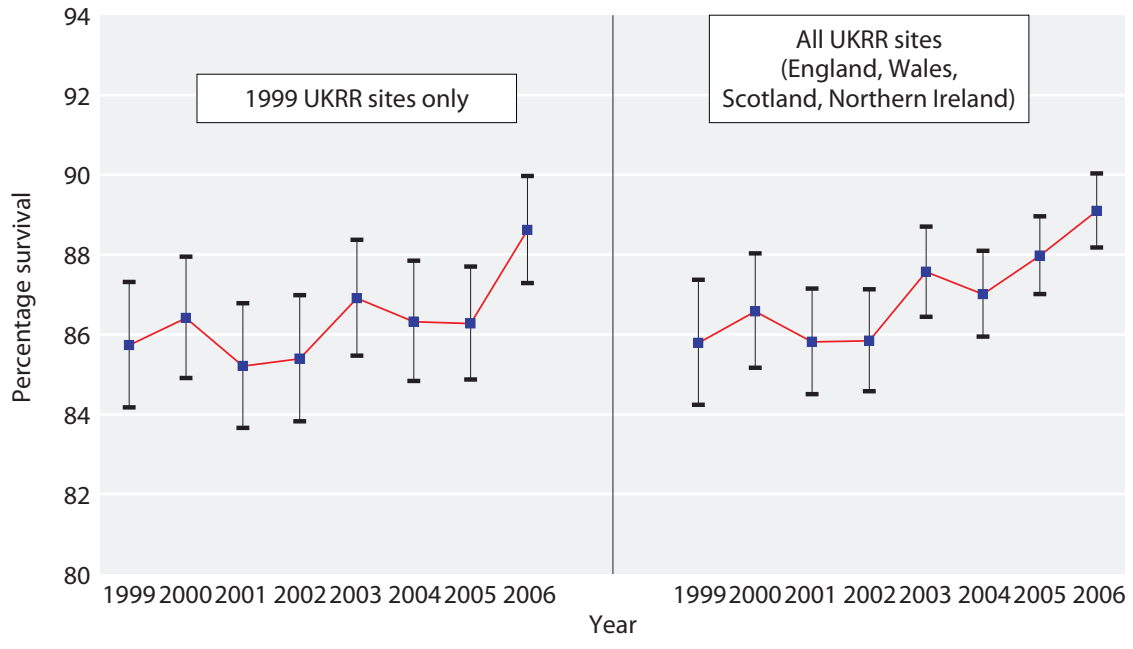

Fig. 7.11. Change in one-year after 90 day adjusted (age 60) survival, 1999-2006 Showing $95 \%$ confidence intervals 


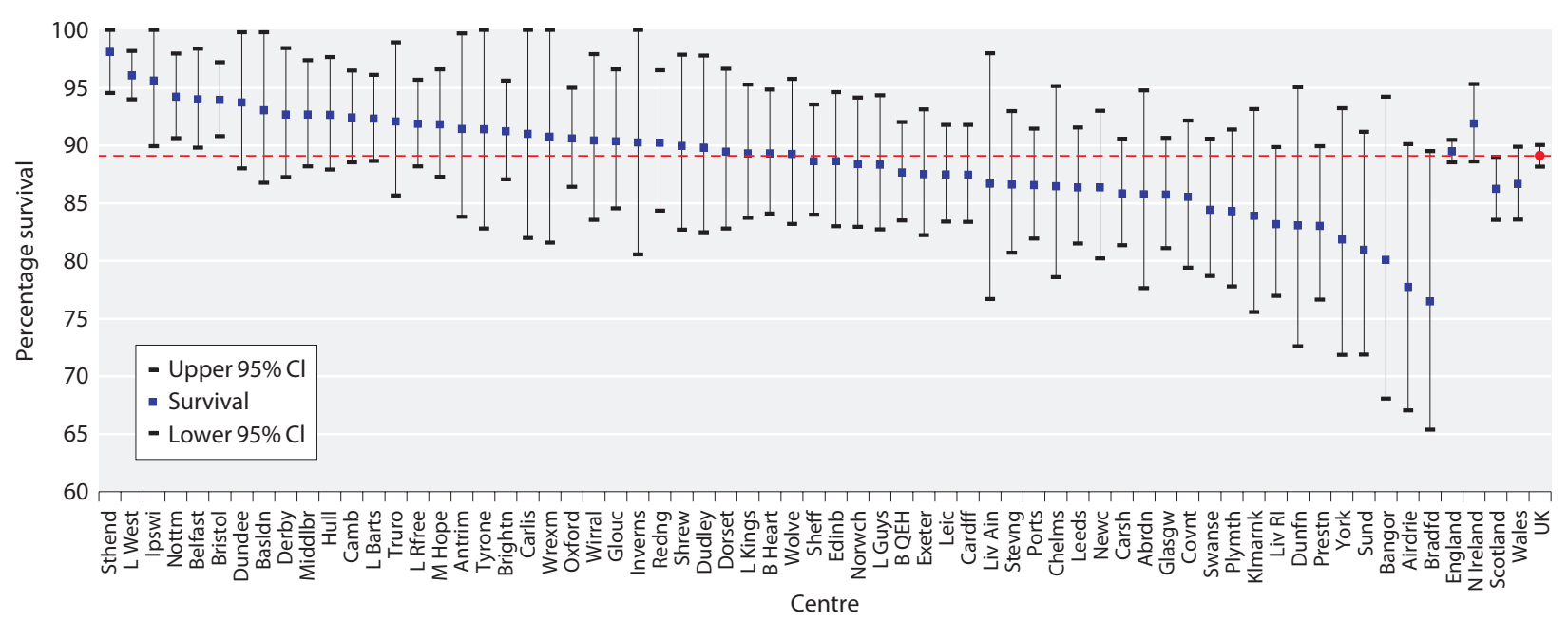

Fig. 7.12. Survival one-year after 90 days, adjusted to age 60, 2006 cohort Showing 95\% confidence intervals

Table 7.11. Adjusted 1 year after 90 day survival 2003-2006

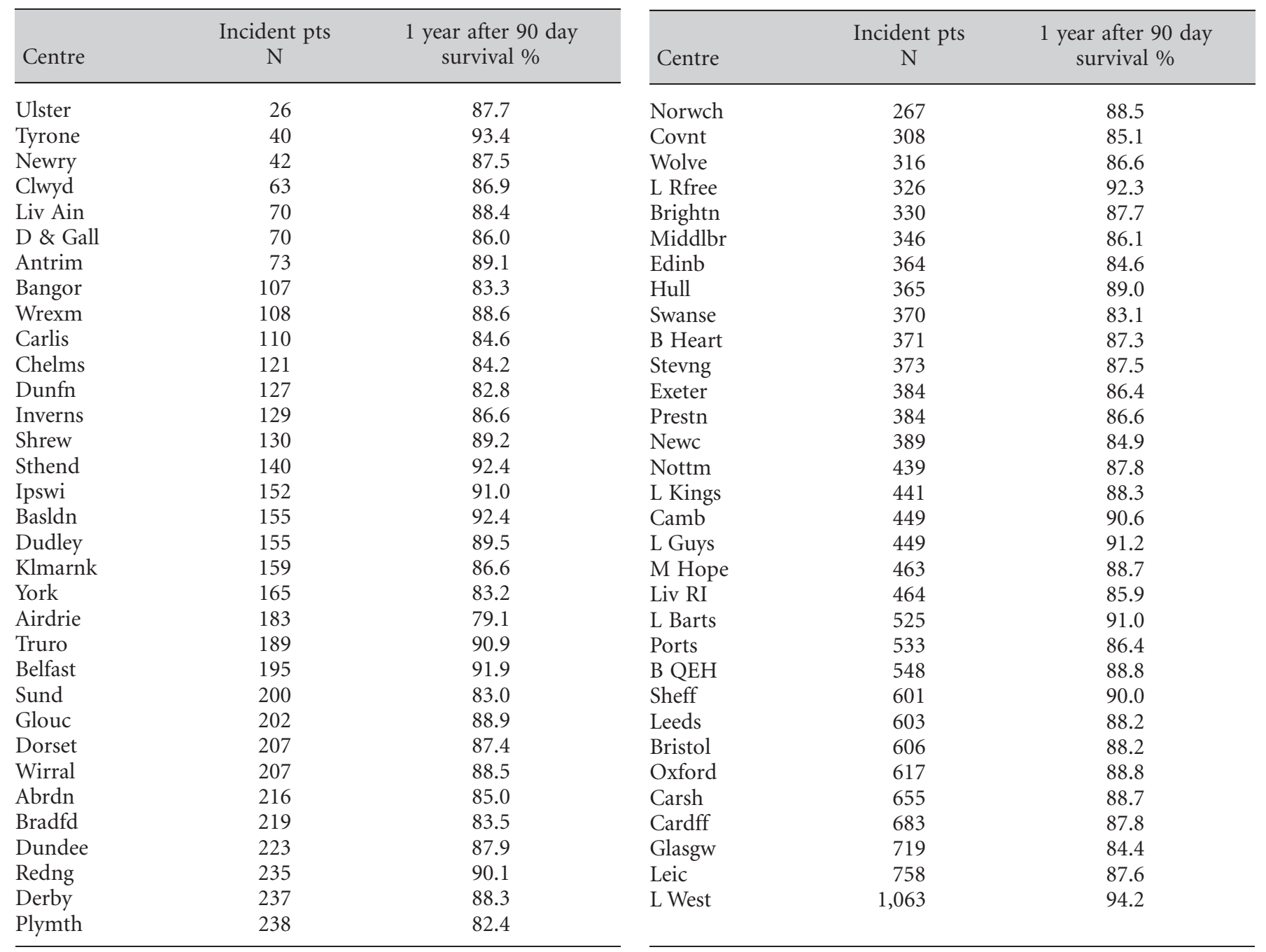

$\mathrm{c} 124$

Nephron Clin Pract 2009;111(suppl 1): c113-c139
Ansell/Roderick/Hodsman/Ford/ Steenkamp/Tomson 
One centre (London West) appears to be an extreme outlier with much better than expected survival. Even after the survival data were re-analysed for the 2006 cohort alone, this centre remained outside the $3 \mathrm{SD}$ limit, with better than expected survival. Removing this centre from the funnel plot (because it is a statistical outlier) and from the calculation of the lower SDs does not alter the number of centres falling below 2 SDs. Reasons for this are actively being investigated, in cooperation with the London West centre. It is unlikely that this may solely be accounted for by ethnic mix as the second year patient survival (survival of RRT patients between month 13 and month 24) is within 2 SDs of expected. Preliminary investigations suggest that there has been over-estimation of the denominator as a result of incorrect inclusion of patients from other centres (predominantly transplant recipients) in the numbers of incident patients. The UKRR identified some under-reporting of deaths (via the use of the NHS tracing service), although these deaths were included in the current survival calculation. Underreporting of incident RRT patients may also play a potential role, although current investigations show this is not causing a significant underestimation of deaths.

There are known regional differences in the life expectancy of the general population within the UK. Table 7.12 shows differences in life expectancy between the UK countries $[4,5]$. The UKRR is investigating ways to adjust centre survival for the differences in the underlying population.

\section{Analysis of the impact of adjustment for comorbidity}

on the 1 year after 90 day survival

Comorbidity returns to the UKRR have remained static (chapter 6). With the de-anonymisation of centre names, it is essential to show what the importance is of adjusting patient survival for comorbidity. Figure 7.14 shows the effect of adjusting for comorbidity. Using the

Table 7.12. Life expectancy 2004-2006 in UK countries (source ONS)

\begin{tabular}{lccccc}
\hline & \multicolumn{2}{c}{ At birth } & & \multicolumn{2}{c}{ At age 65 } \\
\cline { 2 - 3 } \cline { 5 - 6 } Country & Male & Female & & Male & Female \\
\hline England & 77.2 & 81.5 & & 17.1 & 19.9 \\
Wales & 76.6 & 80.9 & & 16.7 & 19.5 \\
Scotland & 74.6 & 79.6 & & 15.8 & 18.6 \\
N Ireland & 76.1 & 81.0 & & 16.6 & 19.5 \\
UK & $\mathbf{7 6 . 9}$ & $\mathbf{8 1 . 3}$ & & $\mathbf{1 6 . 9}$ & $\mathbf{1 9 . 7}$ \\
\hline
\end{tabular}

Survival in UK RRT patients

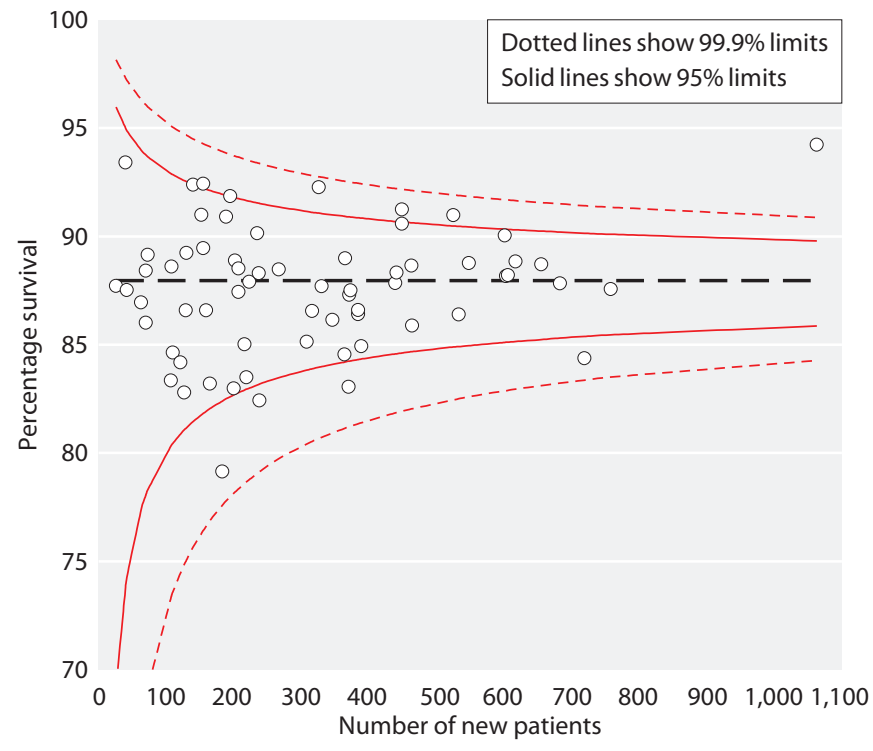

Fig. 7.13. Funnel plot for age adjusted 1 year after 90 days survival, 2003-2006 cohort

(patients who died within the first 90 days have been excluded)

combined incident cohort from 2002-2006, 8 centres had returned comorbidity data for more than $85 \%$ of patients. Adjustment was first performed to age 60 , then to the average primary diagnosis mix for all the 8 centres. Further adjustment was then made to the average diversity of comorbidity present at these centres.

This shows how survival changes with adjustment highlighting the importance of improving the quality of comorbidity returns to the Renal Registry.

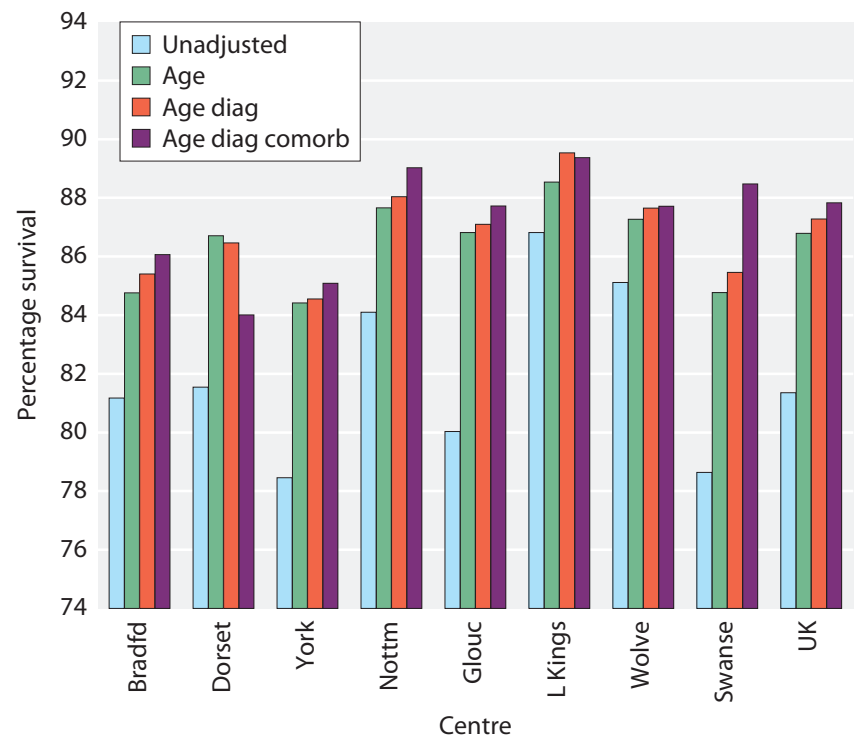

Fig. 7.14. Change in 1 year after 90 day survival after adjustment for age, diagnosis and comorbidity 2002-2006

Nephron Clin Pract 2009;111(suppl 1): 


\section{Results of prevalent patient survival analyses}

Table 7.13 shows the one year survival on dialysis, after censoring at the time of transplantation.

In tables 7.14 and 7.15 the 2007 one year death rate is shown for dialysis and transplanted patients respectively. The median age of prevalent patients in Northern Ireland and Wales was older than those in England.

Figure 7.15 shows the one year survival of prevalent dialysis patients in different age groups on 1/1/2007.

One year survival of prevalent dialysis patients by centre

The age adjusted one year survival of dialysis patients in each centre is shown in table 7.13 and is illustrated in
Table 7.14. One-year death rate per 1,000 dialysis patient years in 2007 by country

\begin{tabular}{lcccc}
\hline & England & N Ireland & Scotland & Wales \\
\hline Death rate & 153 & 154 & 161 & 173 \\
$95 \%$ CI & $147-160$ & $126-186$ & $143-181$ & $149-200$ \\
Median age & 63.6 & 65.7 & 63.4 & 65.7 \\
\hline
\end{tabular}

figures 7.16 and 7.17, dividing the data into those patients aged $<65$ years and those 65 years and over. Figure 7.18 shows the age adjusted data (60 years) and in figure 7.19 as a funnel plot. The solid lines show the 2 standard deviation limit (95\% limits) and the dotted

Table 7.13. Prevalent 1 year $\mathrm{KM}^{*}$ survival of dialysis patients in 2007 , censoring at transplantation (adjusted for age 60 )

\begin{tabular}{|c|c|c|c|}
\hline Centre & $\begin{array}{c}\text { Adjusted } \\
1 \text { year survival }\end{array}$ & $\begin{array}{l}\text { Lower } \\
95 \% \mathrm{CI}\end{array}$ & $\begin{array}{c}\text { Upper } \\
95 \% \mathrm{CI}\end{array}$ \\
\hline Abrdn & 89.6 & 86.0 & 93.4 \\
\hline Airdrie & 78.3 & 72.4 & 84.7 \\
\hline Antrim & 85.4 & 80.8 & 90.4 \\
\hline B Heart & 87.6 & 84.7 & 90.6 \\
\hline B QEH & 88.6 & 86.6 & 90.6 \\
\hline Bangor & 80.7 & 74.2 & 87.8 \\
\hline Basldn & 91.4 & 87.5 & 95.5 \\
\hline Belfast & 90.9 & 88.0 & 93.9 \\
\hline Bradfd & 83.2 & 78.3 & 88.4 \\
\hline Brightn & 87.7 & 84.9 & 90.6 \\
\hline Bristol & 89.3 & 87.0 & 91.7 \\
\hline Camb & 88.3 & 85.5 & 91.1 \\
\hline Cardff & 88.8 & 86.6 & 91.2 \\
\hline Carlis & 87.0 & 81.1 & 93.3 \\
\hline Carsh & 89.0 & 86.8 & 91.2 \\
\hline Chelms & 85.6 & 80.4 & 91.2 \\
\hline Clwyd & 91.1 & 85.4 & 97.1 \\
\hline Covnt & 86.9 & 83.6 & 90.3 \\
\hline D \& Gall & 90.5 & 84.6 & 96.9 \\
\hline Derby & 87.5 & 83.9 & 91.2 \\
\hline Derry & 86.4 & 76.9 & 96.9 \\
\hline Dorset & 86.9 & 82.7 & 91.3 \\
\hline Dudley & 86.7 & 82.0 & 91.7 \\
\hline Dundee & 84.5 & 80.1 & 89.1 \\
\hline Dunfn & 89.2 & 84.6 & 94.2 \\
\hline Edinb & 88.7 & 85.5 & 92.0 \\
\hline Exeter & 87.3 & 84.2 & 90.4 \\
\hline Glasgw & 88.8 & 86.6 & 91.0 \\
\hline Glouc & 87.8 & 83.9 & 91.9 \\
\hline Hull & 89.9 & 87.0 & 92.8 \\
\hline Inverns & 94.2 & 90.4 & 98.2 \\
\hline Ipswi & 85.2 & 79.9 & 90.8 \\
\hline Klmarnk & 87.1 & 82.6 & 91.9 \\
\hline L Barts & 89.1 & 86.9 & 91.4 \\
\hline L Guys & 90.9 & 88.5 & 93.3 \\
\hline L Kings & 84.6 & 81.2 & 88.1 \\
\hline L Rfree & 90.5 & 88.4 & 92.6 \\
\hline
\end{tabular}

\begin{tabular}{|c|c|c|c|}
\hline Centre & $\begin{array}{c}\text { Adjusted } \\
1 \text { year survival }\end{array}$ & $\begin{array}{l}\text { Lower } \\
95 \% \text { CI }\end{array}$ & $\begin{array}{l}\text { Upper } \\
95 \% \text { CI }\end{array}$ \\
\hline L West & 92.8 & 91.5 & 94.1 \\
\hline Leeds & 88.8 & 86.5 & 91.2 \\
\hline Leic & 89.9 & 87.9 & 91.9 \\
\hline Liv Ain & 90.9 & 85.4 & 96.7 \\
\hline Liv RI & 85.8 & 82.9 & 88.8 \\
\hline M Hope & 88.6 & 85.6 & 91.6 \\
\hline M RI & 85.0 & 81.7 & 88.4 \\
\hline Middlbr & 86.7 & 83.1 & 90.5 \\
\hline Newc & 87.2 & 83.7 & 90.9 \\
\hline Newry & 86.7 & 80.9 & 93.0 \\
\hline Norwch & 86.5 & 83.2 & 89.9 \\
\hline Nottm & 89.5 & 87.0 & 92.2 \\
\hline Oxford & 87.8 & 85.3 & 90.3 \\
\hline Plymth & 83.6 & 78.9 & 88.5 \\
\hline Ports & 89.6 & 87.0 & 92.2 \\
\hline Prestn & 90.8 & 88.3 & 93.5 \\
\hline Redng & 89.7 & 86.4 & 93.1 \\
\hline Sheff & 88.4 & 86.1 & 90.8 \\
\hline Shrew & 89.4 & 85.2 & 93.8 \\
\hline Stevng & 89.7 & 87.2 & 92.2 \\
\hline Sthend & 85.8 & 80.8 & 91.1 \\
\hline Stoke & 84.4 & 80.8 & 88.3 \\
\hline Sund & 82.4 & 76.9 & 88.3 \\
\hline Swanse & 88.4 & 85.5 & 91.4 \\
\hline Truro & 88.8 & 85.0 & 92.8 \\
\hline Tyrone & 93.3 & 89.1 & 97.6 \\
\hline Ulster & 89.0 & 82.5 & 96.0 \\
\hline Wirral & 87.8 & 83.7 & 92.1 \\
\hline Wolve & 87.8 & 84.5 & 91.1 \\
\hline Wrexm & 88.8 & 83.9 & 94.0 \\
\hline York & 88.0 & 83.4 & 93.0 \\
\hline England & 88.6 & 88.1 & 89.1 \\
\hline N Ireland & 89.2 & 87.2 & 91.2 \\
\hline Scotland & 88.0 & 86.6 & 89.3 \\
\hline Wales & 88.2 & 86.5 & 89.8 \\
\hline UK & 88.5 & 88.1 & 89.0 \\
\hline
\end{tabular}

${ }^{*}$ Kaplan Meier 
Table 7.15. One-year survival of prevalent RRT patients in UK by modality (unadjusted unless stated otherwise)

\begin{tabular}{|c|c|c|c|c|}
\hline Patient group & Patients & Deaths & $\mathrm{KM}^{*}$ survival & KM 95\% CI \\
\hline \multicolumn{5}{|l|}{ Transplant patients 2007} \\
\hline Censored at dialysis & 17,545 & 395 & 97.7 & $97.5-97.9$ \\
\hline \multicolumn{5}{|l|}{ Dialysis patients 2007} \\
\hline All & 22,115 & 3,046 & 85.7 & $85.2-86.1$ \\
\hline All 1/1/2006 ( 2 year) & 19,937 & 5,109 & 72.5 & $71.9-73.2$ \\
\hline \multicolumn{5}{|l|}{ Dialysis patients 2007} \\
\hline All age $<65$ & 11,693 & 913 & 91.7 & $91.1-92.2$ \\
\hline All age $65+$ & 10,422 & 2,133 & 79.3 & $78.5-80.1$ \\
\hline Non-diabetic $<65$ & 9,121 & 588 & 93.1 & $92.5-93.6$ \\
\hline Diabetic $<65$ & 2,020 & 264 & 86.2 & $84.6-87.7$ \\
\hline Non-diabetic $65+$ & 8,151 & 1,636 & 79.7 & $78.8-80.6$ \\
\hline Diabetic $65+$ & 1,753 & 376 & 78.4 & $76.3-80.2$ \\
\hline
\end{tabular}

${ }^{*} \mathrm{KM}=$ Kaplan-Meier survival

Cohorts of patients alive $1 / 1 / 2007$ unless indicated otherwise

lines the limits for 3 standard deviations (99.9\% limits). With over 60 centres included, it would be expected by chance that 3 centres would fall outside the 95\% (1 in 20) confidence intervals. Figure 7.19 shows 4 centres between the 2-3 SD interval, with 1 clearly below (Airdrie), 2 marginally below (London Kings and Manchester RI) and 1 above 2 SDs (Inverness). Similarly to the incident survival, one centre (London West) was demonstrating a survival that was beyond 3 SDs better than expected. Reasons for this are being investigated.

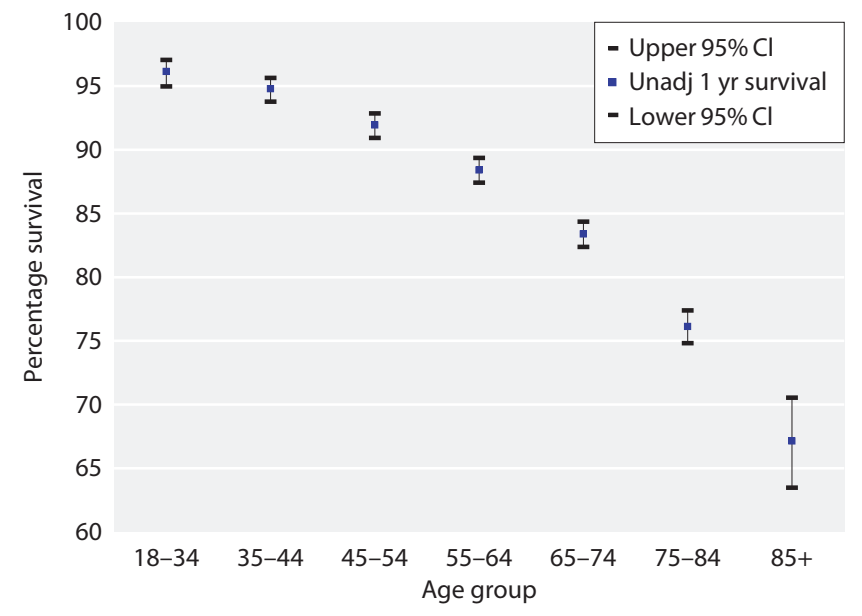

Survival in UK RRT patients
The 2007, one year death rate in prevalent dialysis patients by age band

The death rates on dialysis by age band are shown in figure 7.20. The younger patients are a selected higher risk group, as transplanted patients have been excluded. For a 10 year increase in age in the younger patients, the death rate increased by about 20 per 1,000 patient years compared with an increase of 100 per 1,000 patient years in the older age group. When compared with data from the USRDS report 2007 (the analysis was not

Fig. 7.15. One year survival of prevalent dialysis patients in different age groups -2007

Nephron Clin Pract 2009;111(suppl 1): c113-c139 


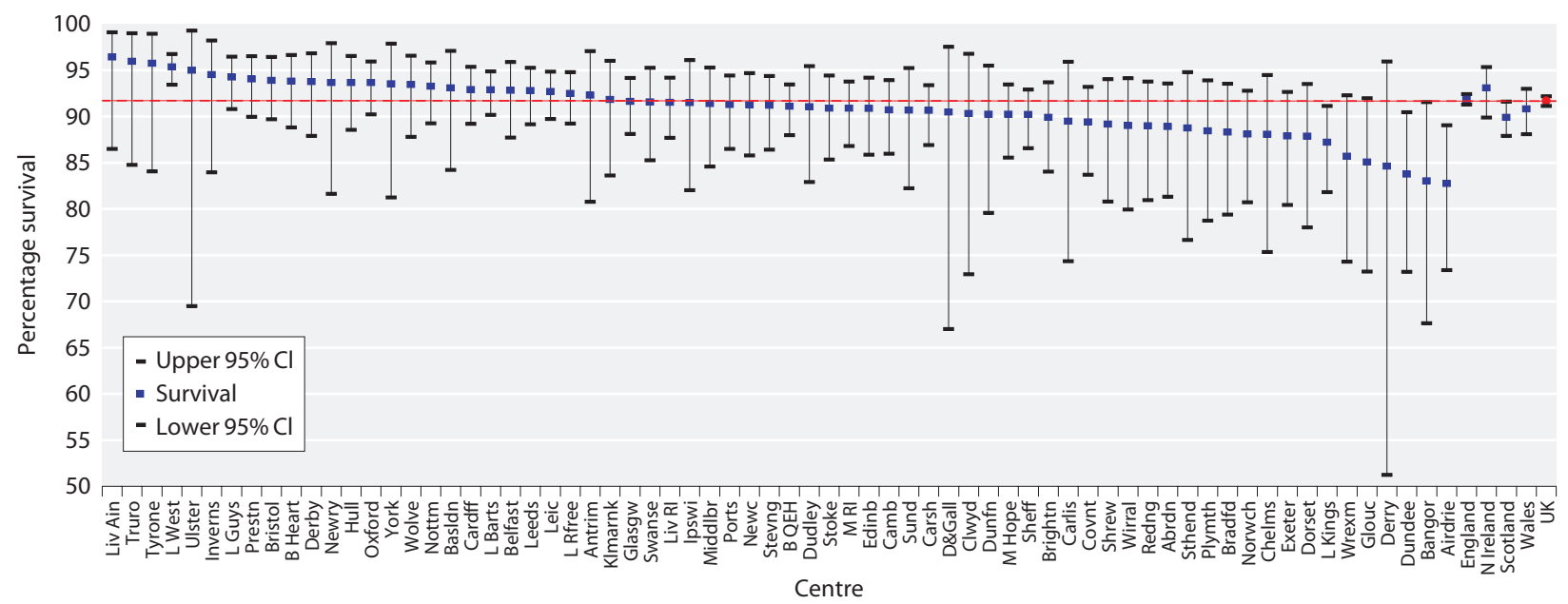

Fig. 7.16. One year survival of prevalent dialysis patients aged under 65 in each centre

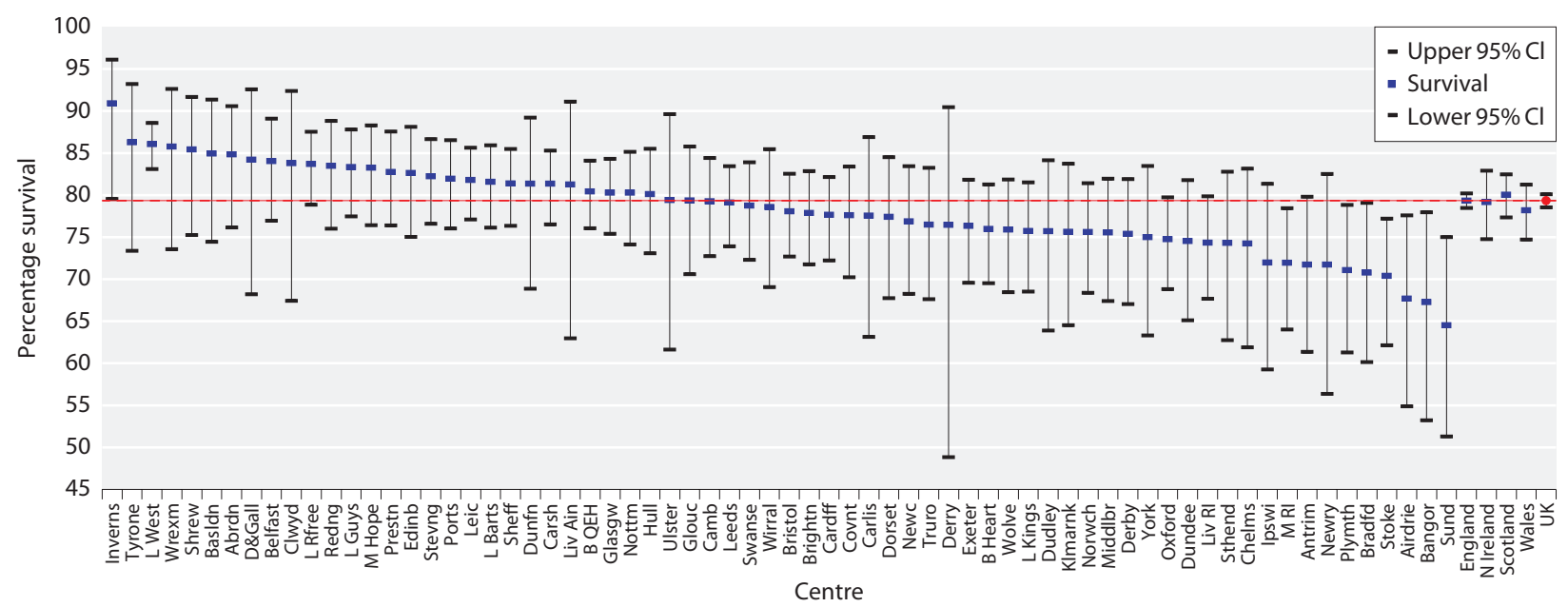

Fig. 7.17. One year survival of prevalent dialysis patients aged 65 and over in each centre

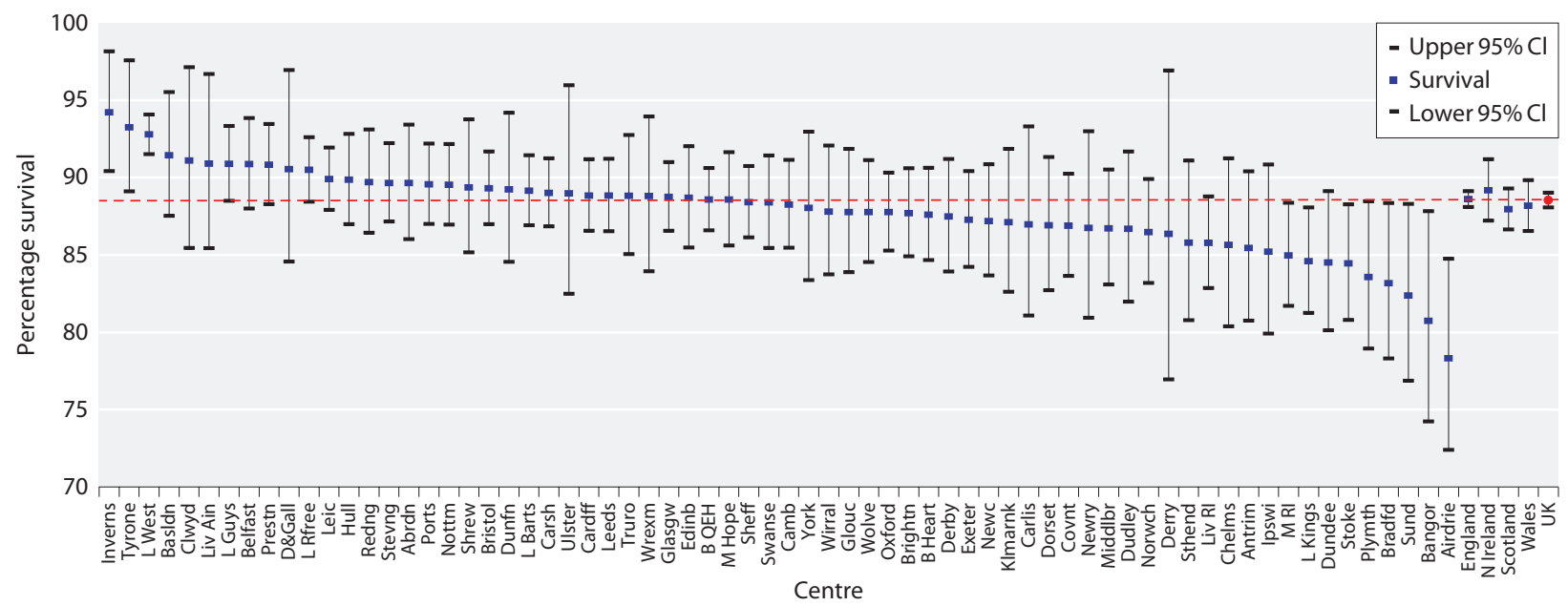

Fig. 7.18. One year survival of prevalent dialysis patients in each centre adjusted to age 60 


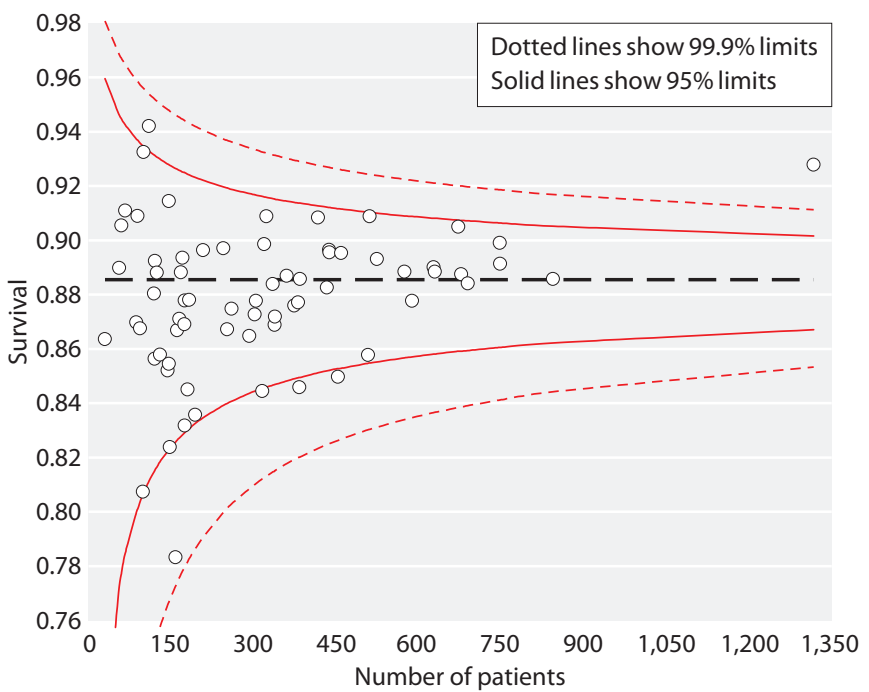

Fig. 7.19. Funnel plot of one year survival of prevalent dialysis patients in each centre adjusted to age 60

repeated in the 2008 USRDS Report), the death rates for UK dialysis patients were lower than dialysis patients in the USA across all age bands (figure 6.12 USRDS) [6].

One year survival of prevalent dialysis patients by $U K$ country from 1997-2007

All UK countries are showing a continued improvement in the age adjusted survival on dialysis (figure 7.21). The change in prevalent survival by centre over the years 2000 to 2006 is shown in this chapter appendix 1, table 7.27.

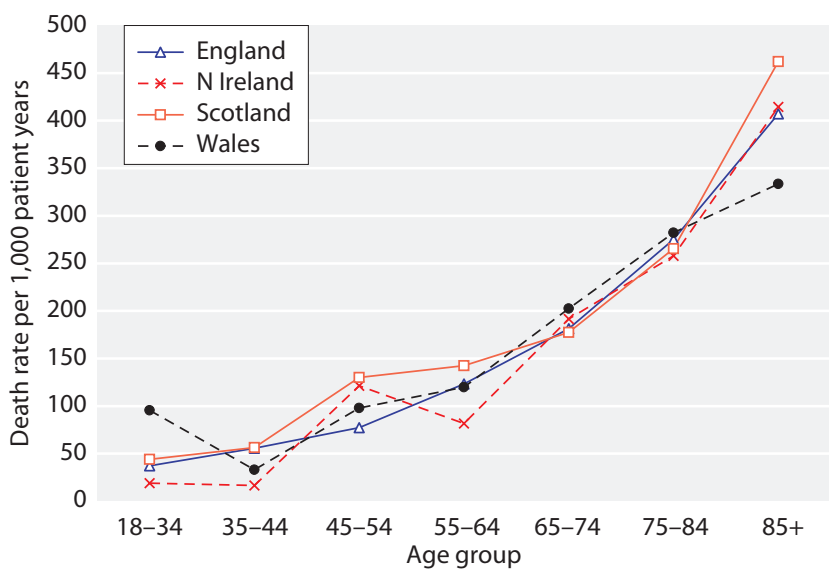

Fig. 7.20. Death rate per 1,000 patient years by UK country and age group for prevalent dialysis patients

One year survival of prevalent dialysis patients with a primary diagnosis of diabetes from 2000-2007

The UK has shown a continued improvement in the age adjusted one year survival of prevalent patients whose primary renal diagnosis was diabetes (table 7.16).

\section{Death rate on RRT compared with the UK general population}

The death rate compared to the general population is shown in table 7.17. Figure 7.22 shows that the relative risk with RRT decreased with age from 30 at age 30 to 3 at age 80 although it still remained higher than that of the general population. With the reduction in rates

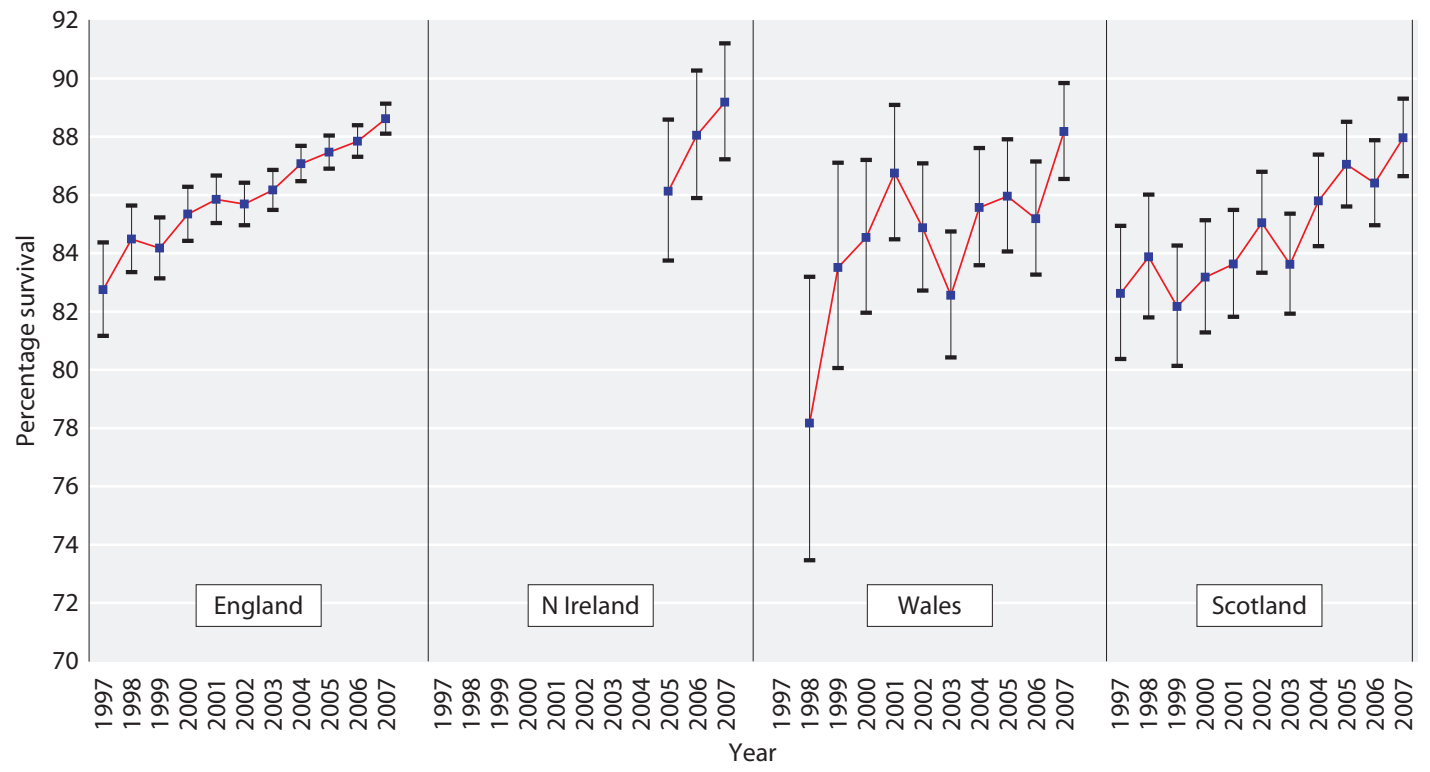

Fig. 7.21. Serial 1 year survival for prevalent dialysis patients by UK country from 1997-2007 adjusted to age 60 Showing $95 \%$ confidence intervals 
Table 7.16. Serial 1 year survival of prevalent dialysis patients with a primary diagnosis of diabetes from 2000-2007

\begin{tabular}{lccccccccc}
\hline Year & 2000 & 2001 & 2002 & 2003 & 2004 & 2005 & 2006 & 2007 \\
\hline 1 year survival & 76.6 & 77.2 & 78.4 & 77.8 & 80.6 & 82.3 & 81.4 & 84.0 \\
\hline
\end{tabular}

Table 7.17. Death rate by age for all prevalent RRT patients on $01 / 01 / 2007$, compared with the general population and with previous analyses in the 1998-2001 cohort

\begin{tabular}{|c|c|c|c|c|c|c|c|c|}
\hline $\begin{array}{l}\text { Age } \\
\text { group }\end{array}$ & $\begin{array}{c}\text { UK } \\
\text { population } \\
\text { mid } 2006 \\
\text { (thousands) }\end{array}$ & $\begin{array}{c}\text { UK } \\
\text { deaths }\end{array}$ & $\begin{array}{c}\text { Death rate } \\
\text { per } 1,000 \\
\text { population }\end{array}$ & $\begin{array}{l}\text { Expected } \\
\text { number of } \\
\text { deaths }\end{array}$ & $\begin{array}{l}\text { UKRR } \\
\text { deaths }\end{array}$ & $\begin{array}{c}\text { UKRR } \\
\text { deaths per } \\
1,000 \text { prev } \\
\text { RRT pts }\end{array}$ & $\begin{array}{l}\text { Observed: } \\
\text { expected } \\
\text { ratio } \\
2002-2006\end{array}$ & $\begin{array}{l}\text { Observed: } \\
\text { expected } \\
\text { ratio } \\
1998-2001\end{array}$ \\
\hline $20-24$ & 4,024 & 2,002 & 0.5 & 0 & 9 & 10.7 & 21.5 & 41.1 \\
\hline $25-29$ & 3,856 & 2,263 & 0.6 & 1 & 22 & 17.7 & 30.1 & 41.8 \\
\hline $30-34$ & 4,040 & 3,053 & 0.8 & 1 & 28 & 15.4 & 20.4 & 31.2 \\
\hline 40-44 & 4,663 & 7,085 & 1.5 & 6 & 101 & 27.9 & 18.3 & 22.6 \\
\hline $45-49$ & 4,151 & 9,864 & 2.4 & 9 & 145 & 38.1 & 16.0 & 19.0 \\
\hline $50-54$ & 3,683 & 14,017 & 3.8 & 14 & 202 & 54.1 & 14.2 & 12.8 \\
\hline $55-59$ & 3,910 & 22,654 & 5.8 & 24 & 257 & 62.8 & 10.8 & 10.1 \\
\hline $60-64$ & 3,240 & 30,213 & 9.3 & 38 & 393 & 97.6 & 10.5 & 10.4 \\
\hline 65-69 & 2,691 & 39,904 & 14.8 & 56 & 489 & 129.5 & 8.7 & 7.9 \\
\hline Total & 45,853 & 565,548 & 12.3 & 532 & 3,660 & 96.8 & 6.9 & 7.7 \\
\hline
\end{tabular}

of death on RRT over the last 10 years this relative risk of death compared with the general population has fallen since the previous analysis in the 2003 Registry Report which compared UKRR mortality data 1998-2001 to national data from 2000.

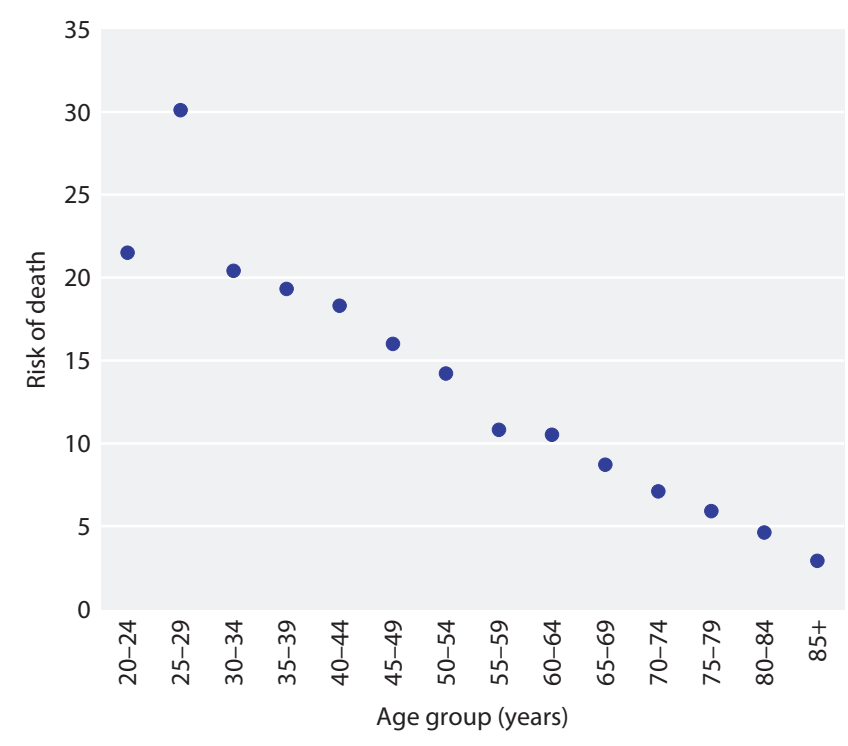

\section{Results of analyses on causes of death}

\section{Data completeness}

The data completeness is shown in table 7.18. Overall it is less than $50 \%$ and has fallen in recent years.
Fig. 7.22. Relative risk of death in all prevalent RRT patients compared with the UK general population in 2007 
Table 7.18. Data completeness of EDTA causes of death by centre by year of start

\begin{tabular}{|c|c|c|c|c|c|c|c|c|}
\hline Centre & 2000 & 2001 & 2002 & 2003 & 2004 & 2005 & 2006 & Total \\
\hline Abrdn & 24.4 & 26.7 & 26.5 & 10.7 & 4.0 & 0.0 & 0.0 & 15.7 \\
\hline Airdrie & 34.1 & 31.1 & 28.9 & 28.1 & 42.3 & 33.3 & 37.5 & 32.9 \\
\hline B Heart & 75.8 & 82.8 & 79.5 & 67.3 & 72.9 & 84.8 & 91.9 & 78.3 \\
\hline B QEH & & & & & 49.4 & 1.9 & 2.5 & 23.8 \\
\hline Bangor & & & 50.0 & 12.5 & 55.0 & 50.0 & 42.1 & 43.3 \\
\hline Bradfd & & 78.9 & 87.5 & 90.9 & 82.8 & 92.6 & 94.7 & 87.3 \\
\hline Brightn & & & & & 3.4 & 4.3 & 6.7 & 4.5 \\
\hline Bristol & 49.5 & 49.5 & 65.8 & 71.4 & 76.5 & 54.9 & 61.3 & 60.5 \\
\hline Camb & 0.0 & 0.0 & 0.0 & 0.0 & 0.0 & 0.0 & 8.1 & 1.2 \\
\hline Cardff & 0.0 & 0.0 & 1.0 & 0.0 & 0.0 & 0.0 & 0.0 & 0.2 \\
\hline Carlis & 33.3 & 30.0 & 64.7 & 61.9 & 78.6 & 81.8 & 100.0 & 56.5 \\
\hline D \& Gall & 92.3 & 72.2 & 90.9 & 81.8 & 72.7 & 91.7 & 83.3 & 82.9 \\
\hline Derby & 36.4 & 38.9 & & 50.0 & 67.9 & 90.5 & 81.3 & 56.0 \\
\hline Dorset & & & & 22.2 & 65.2 & 80.0 & 66.7 & 51.1 \\
\hline Dudley & 33.3 & 5.6 & 33.3 & 0.0 & 0.0 & 0.0 & 0.0 & 11.7 \\
\hline Dundee & 78.1 & 70.6 & 57.8 & 54.3 & 55.9 & 29.7 & 0.0 & 53.7 \\
\hline Dunfn & 80.0 & 84.0 & 78.9 & 58.3 & 69.2 & 61.1 & 44.4 & 72.5 \\
\hline Edinb & 75.8 & 57.9 & 51.1 & 38.3 & 45.5 & 36.4 & 48.1 & 52.4 \\
\hline Exeter & 29.5 & 27.0 & 23.1 & 29.1 & 20.4 & 13.7 & 10.7 & 22.9 \\
\hline Glasgw & 51.0 & 56.6 & 54.6 & 50.0 & 44.1 & 50.7 & 57.4 & 51.9 \\
\hline Glouc & 52.9 & 74.1 & 53.3 & 46.9 & 56.0 & 47.1 & 21.4 & 52.5 \\
\hline Hull & 72.6 & 75.0 & 78.0 & 61.5 & 77.4 & 75.0 & 73.3 & 73.7 \\
\hline Inverns & 11.1 & 0.0 & 0.0 & 0.0 & 0.0 & 9.1 & 0.0 & 2.9 \\
\hline Leic & 71.4 & 77.5 & 83.5 & 83.9 & 83.3 & 78.6 & 72.1 & 78.4 \\
\hline Liv Ain & 0.0 & 0.0 & 0.0 & 0.0 & 0.0 & 44.4 & 75.0 & 58.8 \\
\hline Liv RI & 0.0 & 77.7 & 71.4 & 71.4 & 67.9 & 68.8 & 70.7 & 72.4 \\
\hline M Hope & & & 0.0 & 0.0 & 0.0 & 0.0 & 5.6 & 0.6 \\
\hline Middlbr & 78.7 & 80.4 & 72.3 & 60.3 & 56.3 & 66.7 & 45.0 & 68.3 \\
\hline Newc & & & 43.4 & 19.5 & 36.5 & 50.0 & 48.1 & 38.8 \\
\hline Newry & & & & & & 37.5 & 0.0 & 27.3 \\
\hline Norwch & & & & & 28.9 & 16.4 & 22.9 & 21.9 \\
\hline Nottm & 93.6 & 97.3 & 96.2 & 94.9 & 98.0 & 91.4 & 84.0 & 94.4 \\
\hline Oxford & 9.2 & 6.0 & 4.9 & 3.2 & 5.3 & 4.2 & 0.0 & 5.2 \\
\hline Plymth & 40.4 & 37.0 & 49.0 & 54.5 & 37.8 & 42.3 & 42.9 & 43.7 \\
\hline Ports & & 27.7 & 21.3 & 19.7 & 17.0 & 8.3 & 19.1 & 20.0 \\
\hline Prestn & 72.6 & 74.4 & 68.4 & 68.9 & 58.6 & 60.0 & 55.6 & 68.1 \\
\hline Redng & 69.2 & 58.3 & 75.0 & 87.5 & 100.0 & 70.8 & 100.0 & 76.9 \\
\hline Sheff & 56.8 & 48.2 & 55.1 & 31.4 & 0.0 & 0.0 & 0.0 & 34.3 \\
\hline Shrew & & & & & 54.2 & 46.2 & 36.4 & 47.9 \\
\hline Stevng & 23.9 & 40.3 & 72.9 & 40.7 & 37.9 & 48.4 & 48.3 & 43.0 \\
\hline Sthend & 40.6 & 33.3 & 20.0 & 33.3 & 15.8 & 13.3 & 0.0 & 27.1 \\
\hline Sund & 46.9 & 58.3 & 62.2 & 50.0 & 47.8 & 72.4 & 68.4 & 57.9 \\
\hline
\end{tabular}


Table 7.18. Continued

\begin{tabular}{|c|c|c|c|c|c|c|c|c|}
\hline Centre & 2000 & 2001 & 2002 & 2003 & 2004 & 2005 & 2006 & Total \\
\hline Swanse & 83.0 & 87.7 & 92.1 & 96.1 & 89.8 & 92.5 & 97.0 & 91.0 \\
\hline Truro & & 45.5 & 39.5 & 37.5 & 0.0 & 0.0 & 0.0 & 27.8 \\
\hline Tyrone & & & & & & 50.0 & 71.4 & 58.8 \\
\hline Ulster & & & & & & 75.0 & 75.0 & 75.0 \\
\hline Wirral & & & 53.6 & 75.0 & 64.5 & 63.6 & 55.6 & 63.6 \\
\hline Wolve & 92.9 & 92.0 & 86.8 & 87.2 & 75.0 & 50.0 & 50.0 & 79.9 \\
\hline Wrexm & 7.9 & 0.0 & 6.3 & 0.0 & 0.0 & 0.0 & 25.0 & 3.9 \\
\hline York & 34.4 & 45.8 & 57.1 & 64.5 & 60.9 & 52.6 & 50.0 & 52.4 \\
\hline England & 49.5 & 49.9 & 50.5 & 45.8 & 45.8 & 42.3 & 40.1 & 46.6 \\
\hline $\mathrm{N}$ Ireland & & & & & & 30.3 & 26.3 & 28.9 \\
\hline Scotland & 51.5 & 48.7 & 47.0 & 39.5 & 39.8 & 37.6 & 36.4 & 44.0 \\
\hline Wales & 26.0 & 33.0 & 36.2 & 36.8 & 32.4 & 32.0 & 38.7 & 33.5 \\
\hline UK & 47.7 & 48.3 & 48.7 & 44.2 & 44.0 & 40.4 & 39.2 & 45.0 \\
\hline
\end{tabular}

Blank cells, data not available for that year

Interpretation of patterns of cause of death must be cautious as it is not known whether non-return is associated with cause. Some centres (e.g. Nottingham) consistently achieved a very high rate of data return for cause of death, because a process is in place to make sure that these data are entered. Several centres that were reporting these data in previous years appear to have discontinued collection.

\section{Causes of death in incident RRT patients}

Causes of death within the first 90 days

Treatment withdrawal and infection (table 7.19) were slightly more common as a cause of death within the first 90 days within the patient group aged $>65$ years when compared with the younger age group.
Causes of death within one year after 90 days

Treatment withdrawal as a cause of death (table 7.20) again was more common in the older age group. Cardiac disease accounted for $25 \%$ of all deaths and overall cardiovascular disease for $31 \%$. Infection was still an important cause of nearly 1 in 5 deaths.

Causes of death in prevalent RRT patients in 2007

Causes of death in prevalent RRT patients in 2007 by modality and age

Table 7.21 and figures 7.23 and 7.24 show the frequency of the causes of death for both prevalent dialysis and transplant patients. A comparison has been made with data available from the 2007 ANZDATA Registry report (tables 7.22 and 7.23). The Australian Registry

Table 7.19. Cause of death by age in the first 90 days for incident patients, 2000-2006

\begin{tabular}{|c|c|c|c|c|c|c|}
\hline \multirow[b]{2}{*}{ Cause of death } & \multicolumn{2}{|c|}{ All age groups } & \multicolumn{2}{|c|}{$<65$ years } & \multicolumn{2}{|c|}{$\geqslant 65$ years } \\
\hline & Number of deaths & $\%$ & Number of deaths & $\%$ & Number of deaths & $\%$ \\
\hline Cardiac disease & 399 & 29 & 97 & 31 & 302 & 28 \\
\hline Cerebrovascular disease & 70 & 5 & 17 & 5 & 53 & 5 \\
\hline Infection & 252 & 18 & 43 & 14 & 209 & 19 \\
\hline Malignancy & 112 & 8 & 28 & 9 & 84 & 8 \\
\hline Treatment withdrawal & 205 & 15 & 31 & 10 & 174 & 16 \\
\hline Other & 135 & 10 & 30 & 10 & 105 & 10 \\
\hline Uncertain & 216 & 16 & 64 & 21 & 152 & 14 \\
\hline Total & 1,389 & & 310 & & 1,079 & \\
\hline No cause of death data & 1,594 & & 349 & & 1,245 & \\
\hline
\end{tabular}


Table 7.20. Cause of death by age in 1 year after 90 days for incident patients, 2000-2006

\begin{tabular}{|c|c|c|c|c|c|c|}
\hline \multirow[b]{2}{*}{ Cause of death } & \multicolumn{2}{|c|}{ All age groups } & \multicolumn{2}{|c|}{$<65$ years } & \multicolumn{2}{|c|}{$\geqslant 65$ years } \\
\hline & Number of deaths & $\%$ & Number of deaths & $\%$ & Number of deaths & $\%$ \\
\hline Cardiac disease & 534 & 25 & 165 & 27 & 369 & 24 \\
\hline Cerebrovascular disease & 137 & 6 & 36 & 6 & 101 & 7 \\
\hline Infection & 400 & 19 & 114 & 19 & 286 & 19 \\
\hline Malignancy & 213 & 10 & 79 & 13 & 134 & 9 \\
\hline Treatment withdrawal & 344 & 16 & 51 & 8 & 293 & 19 \\
\hline Other & 373 & 17 & 109 & 18 & 264 & 17 \\
\hline Uncertain & 153 & 7 & 56 & 9 & 97 & 6 \\
\hline Total & 2,154 & & 610 & & 1,544 & \\
\hline No cause of death data & 2,578 & & 730 & & 1,848 & \\
\hline
\end{tabular}

Table 7.21. Cause of death by age in prevalent RRT patients by modality on $1 / 1 / 2007$

\begin{tabular}{|c|c|c|c|c|c|c|}
\hline \multirow[b]{2}{*}{ Cause of death } & \multicolumn{2}{|c|}{ All modalities } & \multicolumn{2}{|c|}{ Dialysis } & \multicolumn{2}{|c|}{ Transplant } \\
\hline & Number of deaths & $\%$ & Number of deaths & $\%$ & Number of deaths & $\%$ \\
\hline Cardiac disease & 316 & 23 & 294 & 24 & 22 & 16 \\
\hline Cerebrovascular disease & 67 & 5 & 57 & 5 & 10 & 7 \\
\hline Infection & 252 & 18 & 223 & 18 & 29 & 21 \\
\hline Malignancy & 118 & 9 & 89 & 7 & 29 & 21 \\
\hline Treatment withdrawal & 179 & 13 & 173 & 14 & 6 & 4 \\
\hline Other & 119 & 9 & 104 & 8 & 15 & 11 \\
\hline Uncertain & 314 & 23 & 287 & 23 & 27 & 20 \\
\hline Total & 1,365 & & 1,227 & & 138 & \\
\hline No cause of death data & 2,296 & & 1,948 & & 348 & \\
\hline
\end{tabular}

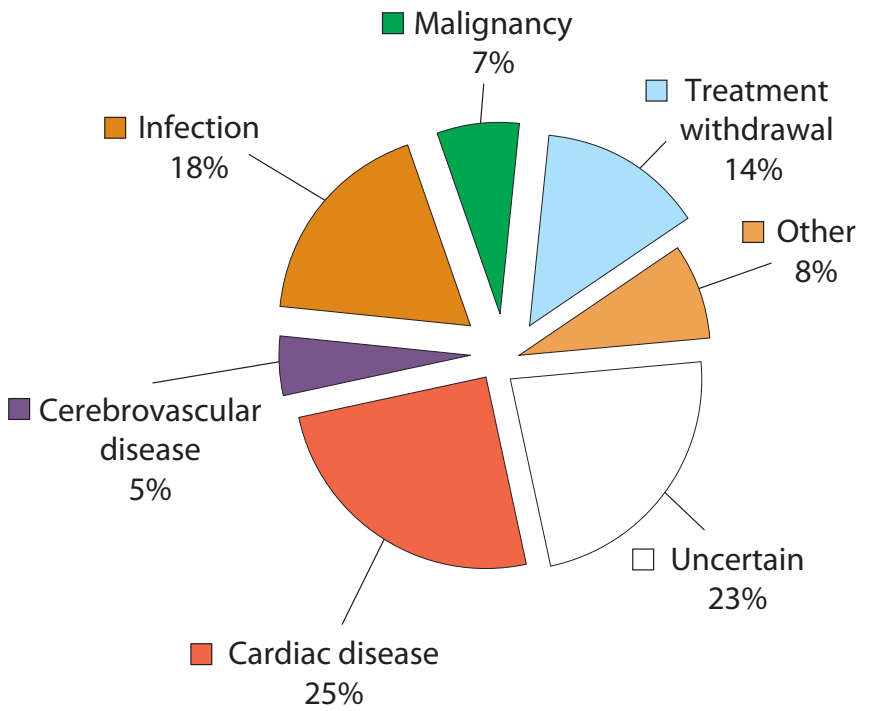

Fig. 7.23. Frequency of causes of death for prevalent dialysis patients in 2007

Survival in UK RRT patients

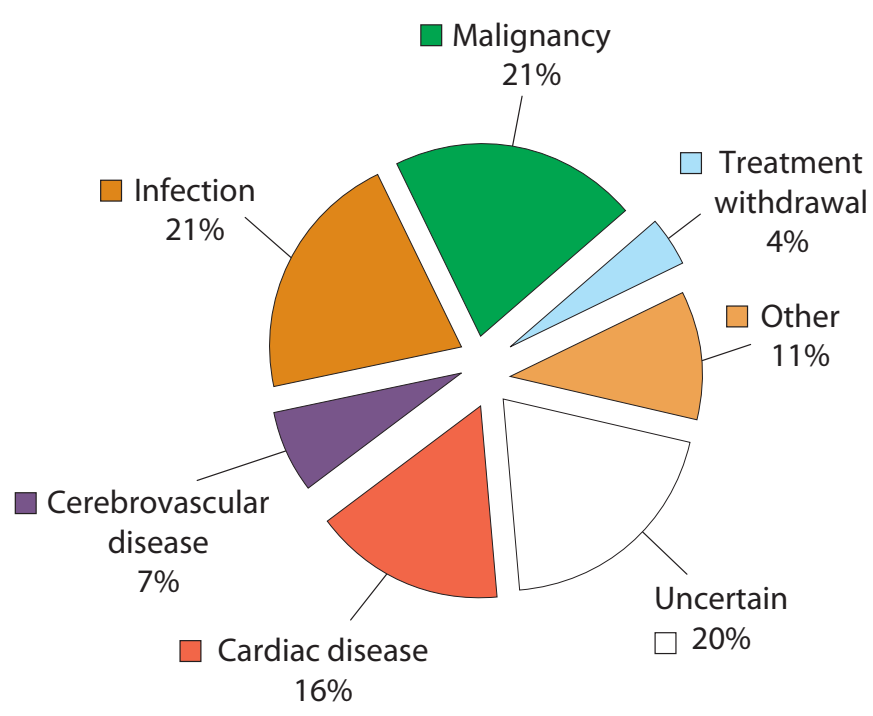

Fig. 7.24. Frequency of causes of death for prevalent transplant patients in 2007

Nephron Clin Pract 2009;111(suppl 1): 
appears to have many fewer cases of 'uncertain' causes of death and infections in both transplant and dialysis patients, this may account for fewer causes of death although this may be due to their difference in classification into the category of 'treatment withdrawal'.

Figure 7.25 contrasts the differences in frequency of these causes, between the 2 modalities within the UK. These data are neither age adjusted nor adjusted for differences in the comorbidity between the 2 groups. As expected, cardiac disease as a cause of death was less common in the transplanted patients as these were a pre-selected low risk group of patients. Treatment withdrawal still occurred in the transplanted group, in patients who chose not to restart dialysis when their renal transplant failed.

In Table 7.22, there were no differences in the causes of death between transplanted patients aged $<55$ or $\geqslant 55$ years. Table 7.23 shows these data for dialysis patients.

Conflict of interest: none

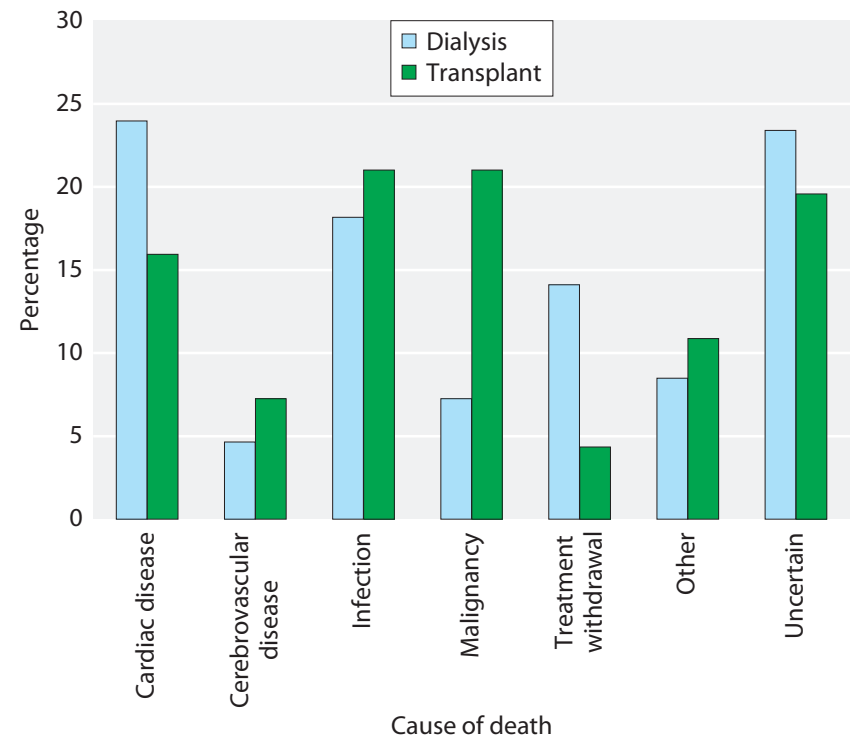

Fig. 7.25. Cause of death by modality for all prevalent patients on $01 / 01 / 2007$

Table 7.22. Cause of death in prevalent transplanted patients on $1 / 1 / 2007$ by age

\begin{tabular}{|c|c|c|c|c|c|c|c|}
\hline \multirow{2}{*}{$\begin{array}{l}\text { Cause of death in } \\
\text { transplanted patients }\end{array}$} & \multicolumn{2}{|c|}{ All age groups } & \multicolumn{2}{|l|}{$<55$ years } & \multicolumn{2}{|l|}{$\geqslant 55$ years } & \multirow{2}{*}{$\begin{array}{c}\text { ANZdata } \\
\%\end{array}$} \\
\hline & Number of deaths & $\%$ & Number of deaths & $\%$ & Number of deaths & $\%$ & \\
\hline Cardiac disease & 22 & 16 & 6 & 17 & 16 & 16 & 30 \\
\hline Cerebrovascular disease & 10 & 7 & 1 & 3 & 9 & 9 & 7 \\
\hline Infection & 29 & 21 & 7 & 19 & 22 & 22 & 15 \\
\hline Malignancy & 29 & 21 & 8 & 22 & 21 & 21 & 32 \\
\hline Treatment withdrawal & 6 & 4 & 2 & 6 & 4 & 4 & 1 \\
\hline Other & 15 & 11 & 6 & 17 & 9 & 9 & 15 \\
\hline Uncertain & 27 & 20 & 6 & 17 & 21 & 21 & 0 \\
\hline Total & 138 & & 36 & & 102 & & \\
\hline No cause of death data & 348 & & 100 & & 248 & & \\
\hline
\end{tabular}

* ANZDATA Registry Report 2007

Table 7.23. Cause of death in prevalent dialysis patients on $1 / 1 / 2007$ by age

\begin{tabular}{|c|c|c|c|c|c|c|c|}
\hline \multirow{2}{*}{$\begin{array}{l}\text { Cause of death in } \\
\text { dialysis patients }\end{array}$} & \multicolumn{2}{|l|}{ All age groups } & \multicolumn{2}{|l|}{$<65$ years } & \multicolumn{2}{|l|}{$\geqslant 65$ years } & \multirow{2}{*}{$\begin{array}{c}\text { ANZdata* } \\
\%\end{array}$} \\
\hline & Number of deaths & $\%$ & Number of deaths & $\%$ & Number of deaths & $\%$ & \\
\hline Cardiac disease & 294 & 24 & 99 & 28 & 195 & 22 & 35 \\
\hline Cerebrovascular disease & 57 & 5 & 14 & 4 & 43 & 5 & 9 \\
\hline Infection & 223 & 18 & 61 & 17 & 162 & 19 & 10 \\
\hline Malignancy & 89 & 7 & 24 & 7 & 65 & 7 & 7 \\
\hline Treatment withdrawal & 173 & 14 & 35 & 10 & 138 & 15 & 34 \\
\hline Other & 104 & 8 & 47 & 13 & 57 & 7 & 5 \\
\hline Uncertain & 287 & 23 & 79 & 22 & 208 & 24 & 1 \\
\hline Total & 1,227 & & 359 & & 868 & & \\
\hline No cause of death data & 1,948 & & 583 & & 1,365 & & \\
\hline
\end{tabular}

* ANZDATA Registry Report 2007 


\section{References}

1. Renal Association. The 2007 4th Renal Association Clinical Practice Guidelines modules 1-5. (http://www.renal.org/pages/pages/clinicalaffairs/guidelines.php)

2. Renal Association. Treatment of Adults and Children with renal failure. Standards and audit measures. 3rd edition. Royal College of Physicians of London, 2002. (http://www.renal.org/Standards/standards.html)

3. US Renal Data System, USRDS 2008 Annual Report Volume 2, Chapter 6 www.usdrs.org/atlas.htm
4. General Register Office for Scotland; 2005 Annual Review; Chapter 1 http://www.gro-scotland.gov.uk/statistics/library/annrep/rgs-annualreview-2005/chapter-1/chapter-1-demographic-overview-deaths/deathspart-1.html\#variationsinmortalitylevelswithinscotland

5. Office for National Statistics http://www.statistics.gov.uk

6. US Renal Data System, USRDS 2007 Annual Report Volume 1, Chapter 6 www.usdrs.org/atlas.htm

\section{Appendix 1: Survival tables}

Table 7.24. One-year after 90-day incident survival by centre for 2006 unadjusted and adjusted to age 60

\begin{tabular}{|c|c|c|c|}
\hline Centre & $\begin{array}{l}\text { Unadjusted } \\
\text { 1yr after 90d } \\
\text { survival }\end{array}$ & $\begin{array}{c}\text { Adjusted } \\
\text { 1yr after 90d } \\
\text { survival }\end{array}$ & $\begin{array}{c}\text { Adjusted } \\
\text { 1yr after 90d } \\
95 \% \mathrm{CI}\end{array}$ \\
\hline Abrdn & 81.1 & 85.8 & $77.6-94.8$ \\
\hline Airdrie & 79.1 & 77.7 & $67.0-90.1$ \\
\hline Antrim & 86.1 & 91.4 & $83.8-99.7$ \\
\hline B Heart & 84.5 & 89.3 & $84.1-94.8$ \\
\hline B QEH & 83.5 & 87.7 & $83.5-92.0$ \\
\hline Bangor & 73.6 & 80.1 & $68.0-94.2$ \\
\hline Basldn & 89.9 & 93.0 & $86.7-99.8$ \\
\hline Belfast & 92.1 & 94.0 & $89.8-98.4$ \\
\hline Bradfd & 73.1 & 76.5 & $65.4-89.5$ \\
\hline Brightn & 87.0 & 91.2 & $87.1-95.6$ \\
\hline Bristol & 91.9 & 93.9 & $90.8-97.2$ \\
\hline Camb & 90.6 & 92.4 & $88.5-96.5$ \\
\hline Cardff & 83.7 & 87.5 & $83.4-91.8$ \\
\hline Carlis & 88.5 & 91.0 & $82.0-100$ \\
\hline Carsh & 79.7 & 85.8 & $81.3-90.6$ \\
\hline Chelms & 78.6 & 86.5 & $78.6-95.1$ \\
\hline Covnt & 82.1 & 85.5 & $79.4-92.2$ \\
\hline Derby & 90.2 & 92.7 & $87.2-98.4$ \\
\hline Dorset & 84.6 & 89.5 & $82.8-96.6$ \\
\hline Dudley & 85.0 & 89.8 & $82.5-97.8$ \\
\hline Dundee & 91.3 & 93.7 & $88.0-99.8$ \\
\hline Dunfn & 80.0 & 83.1 & $72.6-95.0$ \\
\hline Edinb & 86.5 & 88.6 & $83.0-94.6$ \\
\hline Exeter & 81.5 & 87.5 & $82.2-93.1$ \\
\hline Glasgw & 82.1 & 85.7 & $81.1-90.6$ \\
\hline Glouc & 85.7 & 90.4 & $84.5-96.6$ \\
\hline Hull & 91.3 & 92.7 & 87.9-97.7 \\
\hline Inverns & 87.6 & 90.2 & $80.6-100$ \\
\hline Ipswi & 94.0 & 95.6 & $89.9-100$ \\
\hline Klmarnk & 77.9 & 83.9 & $75.6-93.1$ \\
\hline L Barts & 91.5 & 92.3 & $88.6-96.1$ \\
\hline L Guys & 87.9 & 88.3 & $82.7-94.3$ \\
\hline L Kings & 87.5 & 89.3 & $83.7-95.3$ \\
\hline
\end{tabular}

\begin{tabular}{|c|c|c|c|}
\hline Centre & $\begin{array}{l}\text { Unadjusted } \\
\text { 1yr after 90d } \\
\text { survival }\end{array}$ & $\begin{array}{c}\text { Adjusted } \\
\text { 1yr after 90d } \\
\text { survival }\end{array}$ & $\begin{array}{c}\text { Adjusted } \\
\text { 1yr after 90d } \\
95 \% \mathrm{CI}\end{array}$ \\
\hline L Rfree & 91.0 & 91.9 & $88.2-95.7$ \\
\hline L West & 95.3 & 96.1 & $94.0-98.2$ \\
\hline Leeds & 83.6 & 86.4 & $81.5-91.5$ \\
\hline Leic & 84.9 & 87.5 & $83.4-91.8$ \\
\hline Liv Ain & 84.8 & 86.7 & 76.7-98.0 \\
\hline Liv RI & 81.9 & 83.2 & $77.0-89.9$ \\
\hline M Hope & 90.6 & 91.8 & $87.3-96.6$ \\
\hline Middlbr & 90.5 & 92.7 & $88.2-97.4$ \\
\hline Newc & 84.9 & 86.4 & $80.2-93.0$ \\
\hline Norwch & 82.9 & 88.4 & $83.0-94.1$ \\
\hline Nottm & 92.1 & 94.2 & $90.6-97.9$ \\
\hline Oxford & 88.7 & 90.6 & $86.4-95.0$ \\
\hline Plymth & 78.7 & 84.3 & $77.8-91.4$ \\
\hline Ports & 82.4 & 86.5 & 81.9-91.4 \\
\hline Prestn & 78.5 & 83.0 & $76.6-89.9$ \\
\hline Redng & 86.5 & 90.2 & $84.4-96.5$ \\
\hline Sheff & 86.6 & 88.6 & $84.0-93.5$ \\
\hline Shrew & 87.8 & 90.0 & 82.7-97.9 \\
\hline Stevng & 84.1 & 86.6 & $80.7-93.0$ \\
\hline Sthend & 97.6 & 98.1 & $94.5-100$ \\
\hline Sund & 76.0 & 80.9 & $71.9-91.2$ \\
\hline Swanse & 76.7 & 84.4 & 78.7-90.6 \\
\hline Truro & 88.0 & 92.1 & $85.7-98.9$ \\
\hline Tyrone & 87.5 & 91.4 & $82.8-100$ \\
\hline Wirral & 88.2 & 90.4 & $83.5-97.9$ \\
\hline Wolve & 86.2 & 89.3 & $83.2-95.8$ \\
\hline Wrexm & 87.6 & 90.7 & $81.6-100$ \\
\hline York & 77.0 & 81.8 & $71.8-93.2$ \\
\hline England & 86.6 & 89.5 & $88.5-90.5$ \\
\hline N Ireland & 88.6 & 91.9 & $88.6-95.3$ \\
\hline Scotland & 82.8 & 86.2 & $83.5-89.0$ \\
\hline Wales & 81.7 & 86.7 & $83.6-89.9$ \\
\hline UK & 86.0 & 89.1 & $88.2-90.0$ \\
\hline
\end{tabular}

Survival in UK RRT patients 
Table 7.25. Ninety day incident survival by centre for 2006 unadjusted and adjusted to age 60

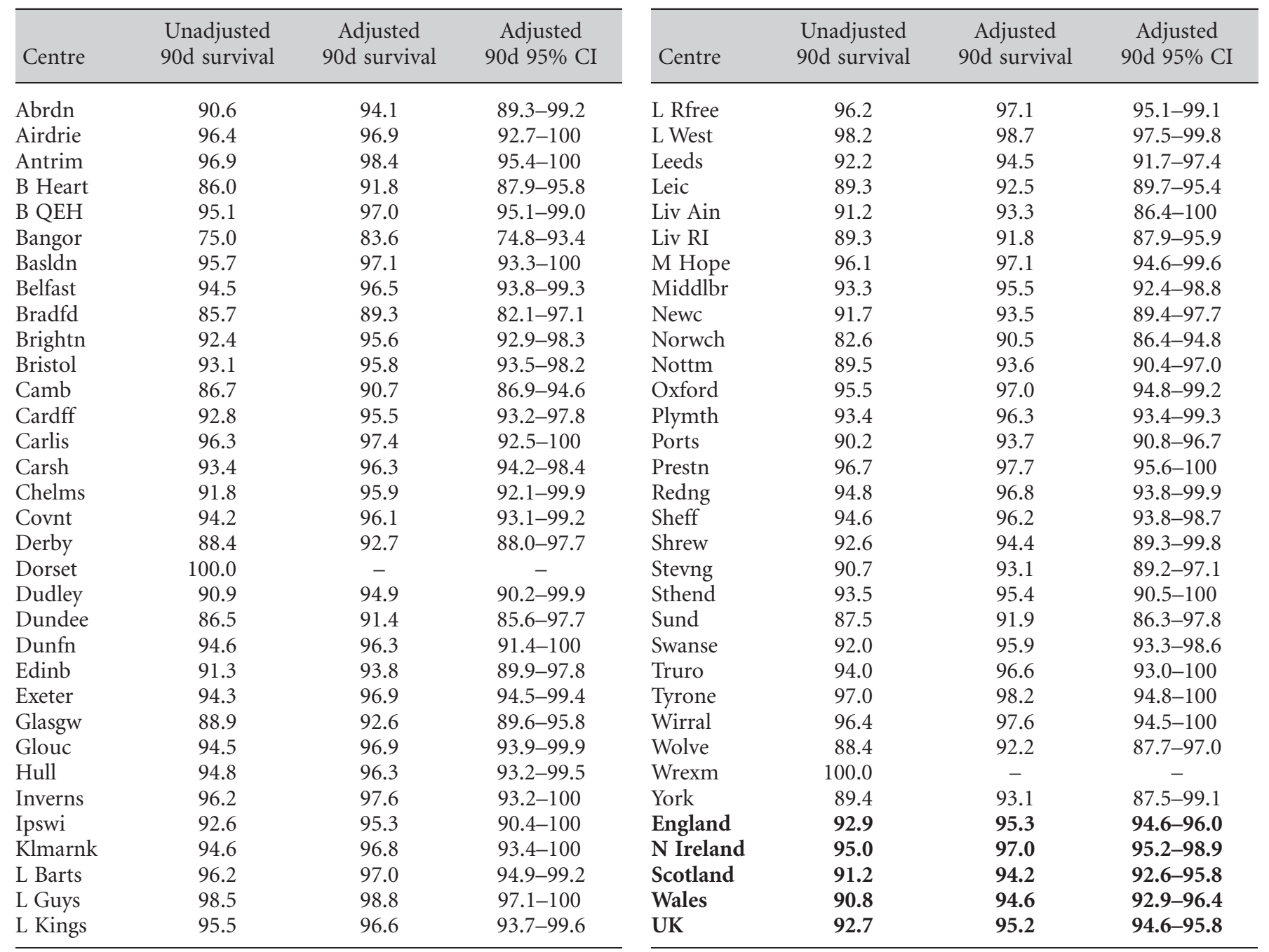

Table 7.26. One year after 90-day incident survival by centre for incident cohort years 1999-2006 adjusted to age 60

\begin{tabular}{|c|c|c|c|c|c|c|c|c|}
\hline Centre & 1999 & 2000 & 2001 & 2002 & 2003 & 2004 & 2005 & 2006 \\
\hline Abrdn & 81.8 & 79.8 & 92.4 & 87.9 & 82.9 & 89.8 & 80.1 & 85.8 \\
\hline Airdrie & 74.8 & 81.6 & 84.8 & 78.4 & 80.0 & 85.6 & 72.3 & 77.7 \\
\hline B Heart & 86.6 & 82.7 & 85.1 & 87.8 & 86.3 & 88.0 & 86.1 & 89.3 \\
\hline $\mathrm{B}$ QEH & & & & & & 88.2 & 90.7 & 87.7 \\
\hline Bangor & & & & 82.2 & 86.9 & 84.0 & 83.4 & 80.1 \\
\hline Bradfd & & & 93.1 & 85.2 & 83.9 & 85.5 & 85.6 & 76.5 \\
\hline Brightn & & & & & & 87.9 & 83.0 & 91.2 \\
\hline Bristol & 85.7 & 86.3 & 85.8 & 88.4 & 87.3 & 87.5 & 83.3 & 93.9 \\
\hline Camb & & & 90.7 & 82.0 & 89.4 & 87.9 & 91.2 & 92.4 \\
\hline Cardff & 88.3 & 88.7 & 83.6 & 82.7 & 89.6 & 86.3 & 88.5 & 87.5 \\
\hline Carlis & - & 79.4 & - & 88.4 & 78.3 & 86.5 & 82.8 & 91.0 \\
\hline
\end{tabular}

c136
Nephron Clin Pract 2009;111(suppl 1): c113-c139
Ansell/Roderick/Hodsman/Ford/ Steenkamp/Tomson 
Table 7.26. Continued

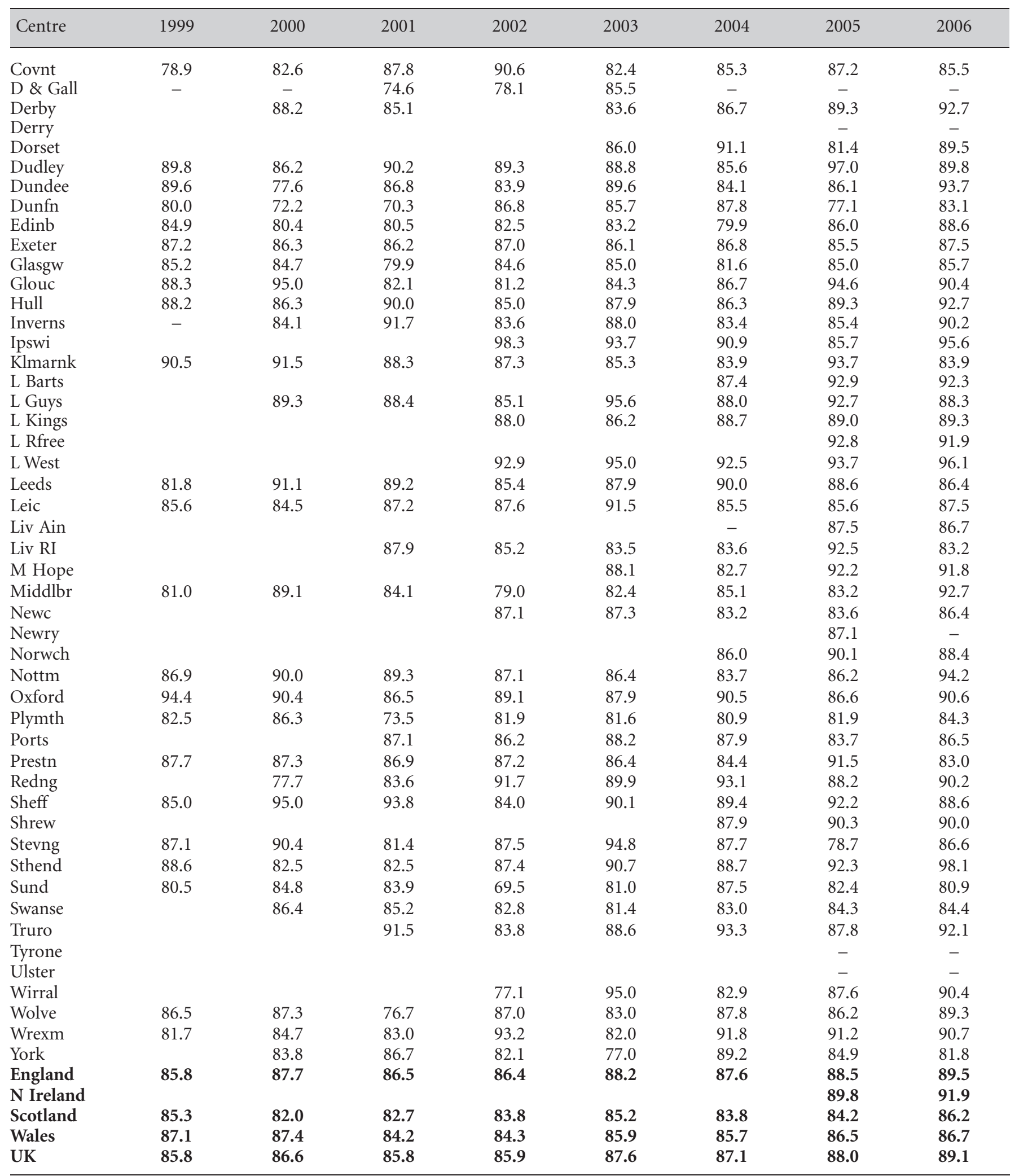

- Centres with $<20$ patients are excluded for that year

Blank cells, data not available for that year 
Table 7.27. One year prevalent survival by centre for prevalent cohort years 2000-2007 adjusted to age 60

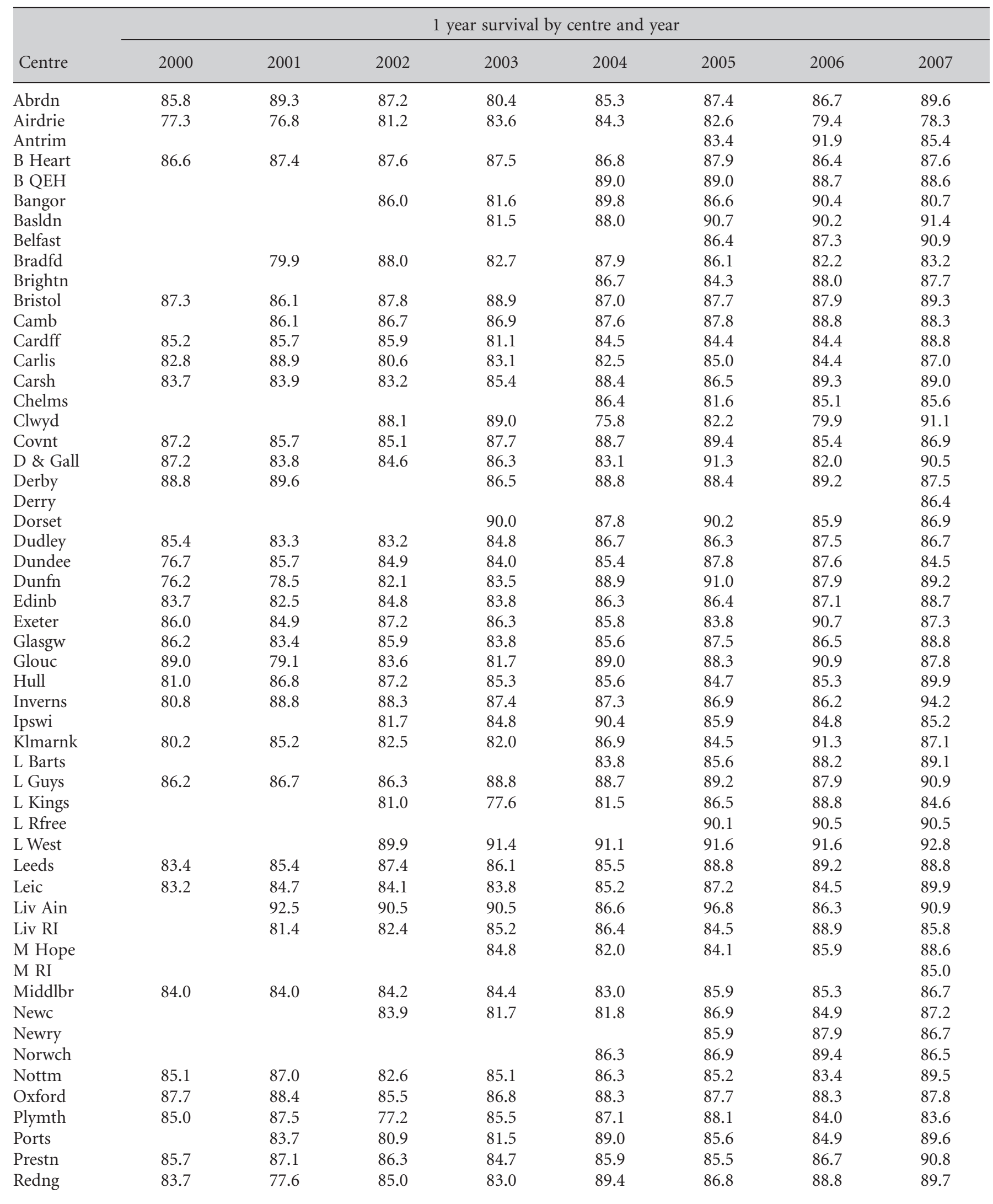

$\mathrm{c} 138$

Nephron Clin Pract 2009;111(suppl 1): c113-c139

Ansell/Roderick/Hodsman/Ford/ Steenkamp/Tomson 
Table 7.27. Continued

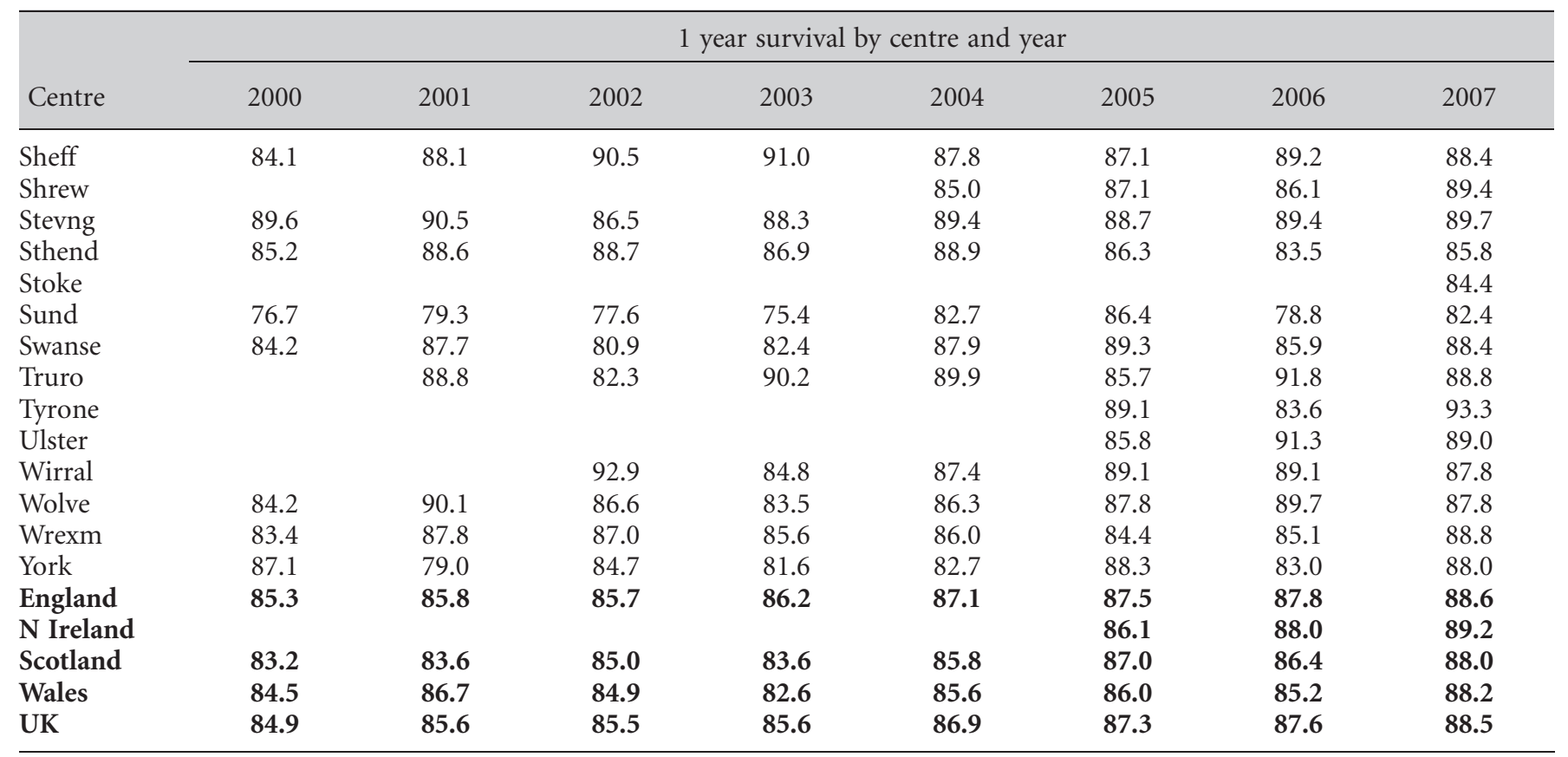

Blank cells, data not available for that year 
